This is the peer reviewed version of the following article: Eur. J. Org. Chem. 2015, 1173-1188, which has been published in final form http://onlinelibrary.wiley.com/doi/10.1002/ejoc.201403042/abstract This article may be used for non-commercial purposes in accordance with http://olabout.wiley.com/WileyCDA/Section/id-

\title{
Organocatalysis on Tap: Enantioselective Continuous Flow Processes Mediated by Solid-Supported Chiral Organocatalysts
}

\author{
Carles Rodríguez-Escrich ${ }^{*[a]}$ and Miquel A. Pericàs*[a],[b] \\ Dedicated to Prof. Javier de Mendoza on the occasion of his $70^{\text {th }}$ birthday
}

\begin{abstract}
Sustainability concerns are reshaping the way chemists work, not only at the stage of process design, but also when actually performing reactions. This change of paradigm is exemplified by the deployment of continuous flow techniques, which are slowly becoming a mainstream practice. Indeed, the possibility of performing catalytic processes (the flagship of sustainable chemistry) in flow presents distinctive advantages. Thus, several authors are focusing their efforts in trying to get the best of these two worlds, with the consequent challenge of finding common solutions for their respective issues. In the last years, this approach has been taken one step further with the use in flow processing of enantioselective organocatalysts, which allow the production of enantiopure compounds free of metal contaminants. Herein, we will cover the literature concerning the use of solid-supported organocatalysts for the continuous flow production of enantiomerically enriched compounds.
\end{abstract}

\section{Introduction}

Despite the widespread use of continuous flow techniques in the chemical and petrochemical industries ${ }^{[1]}$ its deployment in the production of fine chemicals and in academic environments is relatively recent. ${ }^{[2]}$ However, the ice has been broken and the general reluctance that synthetic chemists felt about working with pumps, connectors or microreactors (perceived as an incursion into the intricate kingdom of chemical engineering) seems to be a matter of the past. As a consequence, an increasing number of research groups are realizing that flow chemistry is not meant to supersede flask chemistry, but to nicely complement it. ${ }^{[2 b, 2 h]}$ The advantages of this set of methods are quite apparent, even for chemists who have never used them: (a) the scale-up of chemical reactions (perhaps the biggest nightmare of process chemists) becomes a trivial matter ${ }^{[3]}$ with two equally simple solutions, namely, numbering up and extending the operation time of the flow process, (b) in the case of working with hazardous compounds or reactions, the risk of personal injuries is reduced ${ }^{[4]}$ since the reacting volumes at a given time are much smaller, (c) it allows much more accurate control of some reaction parameters, ${ }^{[5]}$ avoiding exotherms, overreaction or catalyst inhibition by the product and (d) it facilitates the achievement of more sustainable laboratory practices ${ }^{[6]}$ in terms of reduced solvent volume, chemical waste and energy consumption.

Nowadays, catalysis is widely recognized as one of the flagships of sustainability in a chemical context. Thus, it is not surprising that one of the most active research areas within the flow chemistry community is the enantioselective catalysis of processes in a continuous manner. ${ }^{[7]}$ Such a problem has been tackled mainly in two ways: by mixing a soluble catalyst in the solution being pumped ${ }^{[8]}$ (Figure 1a) or by the use of species immobilized onto solid support ${ }^{[9]}$ (Figure 1b). Both strategies hold a lot of potential, but the latter has two additional benefits: the product is not contaminated with catalyst and, if this proves robust enough, the catalyst loading becomes a function of time. This leads to a seemingly paradoxical situation

[a] Dr. Carles Rodríguez-Escrich, Prof. Dr. Miquel A. Pericàs. Institute of Chemical Research of Catalonia (ICIQ) Avinguda Països Catalans 16, 43007, Tarragona (Spain) Fax: (+34) 977-920-243 E-mail: mapericas@iciq.es http://www.iciq.org/research/research_group/prof-miquel-a-pericas/ [b] Prof. Dr. Miquel A. Pericàs, Departament de Química Orgànica, Universitat de Barcelona, 08080 Barcelona (Spain) where extremely high turnover numbers (TON) can be achieved for the overall process, whereas at any given time the substrates are exposed to (super)stoichiometric amounts of catalyst inside the reactor. 


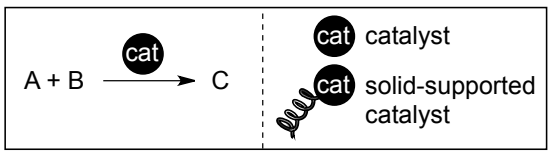

(a) Enantioselective catalysis in flow with a soluble catalyst

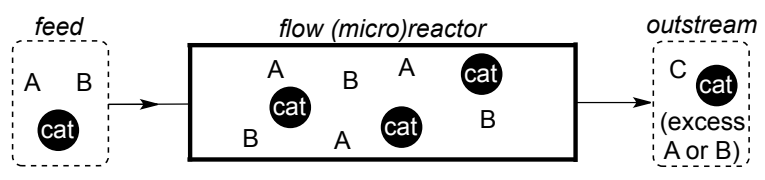

(b) Enantioselective catalysis in flow with an immobilized catalyst

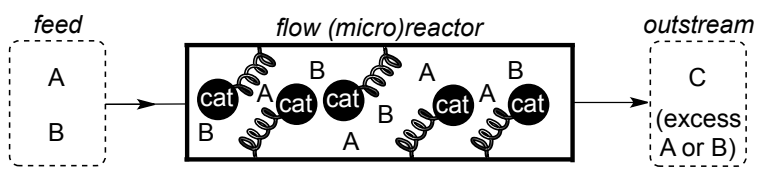

\begin{tabular}{|l|l|}
\multicolumn{1}{c|}{ Advantages } & \multicolumn{1}{c|}{ Issues } \\
\hline -TON becomes a function of time \\
- Outstream free of catalyst
\end{tabular}$\quad \begin{aligned} & \text { • Catalyst is more expensive } \\
& \text { •Deactivation of the catalyst }\end{aligned}$

Figure 1. Enantioselective flow catalysis with (a) soluble species or (b) solid-supported catalysts.

Indeed, the immobilization of enantioselective catalysts and ligands ${ }^{[10]}$ has long been established as an approach that allows the recovery and reuse of these usually expensive molecules. However, examples on the use of such heterogenized species in continuous flow remain scarce ${ }^{[7 a, c, d]}$ despite the potential it could have in the manufacture of enantiopure compounds. In this Microreview we will strive to cover the literature related to the use of supported organocatalysts ${ }^{[11]}$ in enantioselective flow processes. As usual, several classifications were possible: interaction between catalyst and support (covalent, ionic), type of solid support $^{[12]}$ (polystyrene, silica, etc.) or type of catalytic microreactor (packed bed, functionalized inner wall, monolith), among others. In this case, however, we have decided to tackle this subject from the point of view of reactivity, organizing the examples according to the type of organocatalyst supported. In spite of this classification, the importance of experimental set-ups cannot be overemphasized. Therefore, and considering that many readers might not be experienced in flow chemistry techniques, simplified schemes will be included for every example.

Organocatalysts ${ }^{[13]}$ are hard to match from the point of view of the chemist interested in supporting species for flow chemistry. The non-involvement of coordinated metals reduces the risk of leaching of the catalytically active species. Moreover, the fact that the oxidation state of the chiral promoter does not change during the catalytic event contributes to extend the efficiency of the supported catalysts. However, not all that glitters is gold; organocatalytic processes tend to require high loadings ${ }^{[14]}$ and, even under these conditions, the reactions can be slow. This can lead to flow processes which only operate at very low flow rates. In this scenario, it is the chemists' task to evaluate if carrying the reaction in batch and recycling the catalyst might actually be more efficient in terms of productivity, yield or energy efficiency.

Even though it cannot be strictly considered a supported organocatalyst, it is worth mentioning a precedent developed by Itsuno, one of the pioneers in the use of polymer-supported ligands for batch ${ }^{[15]}$ and flow, ${ }^{[16]}$ together with Fréchet, ${ }^{[17]}$ Soai ${ }^{[18]}$ or Ellman.${ }^{[19]}$ Thus, in 1996, Itsuno and co-workers reported the preparation of the oxazaborolidine-decorated resin 1, prepared by co-polymerization of an amino alcohol derivative and subsequent reaction with borane. This catalyst was applied to the asymmetric Diels-Alder reaction between cyclopentadiene and methacrolein and, in a visionary approach, an asymmetric continuous flow processes was implemented. ${ }^{[20]}$ The reagents percolated through the column driven by gravity and, in two consecutive runs of $6 \mathrm{~h}$, ca. $7 \mathrm{~g}$ of the cycloadduct 2 could be obtained in $71 \%$ ee (Scheme 1). 


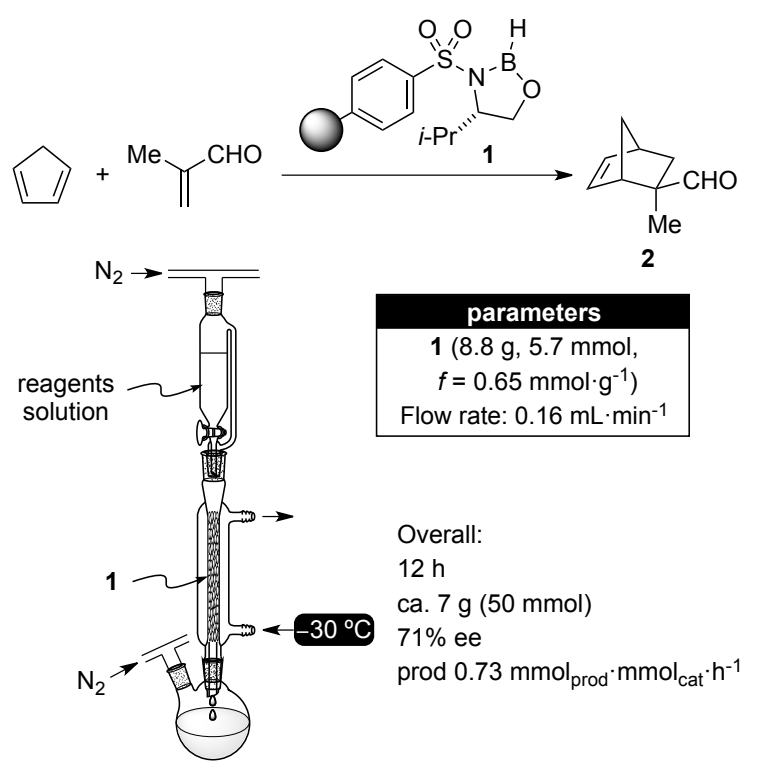

Scheme 1. Continuous flow Diels-Alder reaction catalyzed by the polymer-supported oxazaborolidine 1.

\section{Supported Cinchona Alkaloid Derivatives}

\subsection{Early examples: gravity or pressure driven}

In the year 2000, Lectka et al. reported the first example of enantioselective organocatalysis with supported species operating under continuous flow, although at the time the term organocatalysis was still in the process of being coined. The approach could not be simpler: three columns were assembled in series, the first one with a polymer-supported base, the next one with the immobilized catalyst and, at the end, a scavenger to prevent the non-reacted material from contaminating the outstream. ${ }^{[21]}$ In this manner, starting from acyl chlorides (3), the corresponding ketenes (4) were generated with PS-BEMP ${ }^{[22]}$ (5, a supported phosphazene base) at the first column. Then, these were reacted with a sulfonylimine (6) in a process mediated by a cinchona alkaloid derivative supported on a Wang resin (7). Finally, resin 8 was chosen as a scavenger in order to capture the unreacted ketene and imine (Scheme 2). Thus, by simply pouring THF solutions of the reagents down the columns, enantioenriched $\beta$-lactams could be conveniently prepared. 

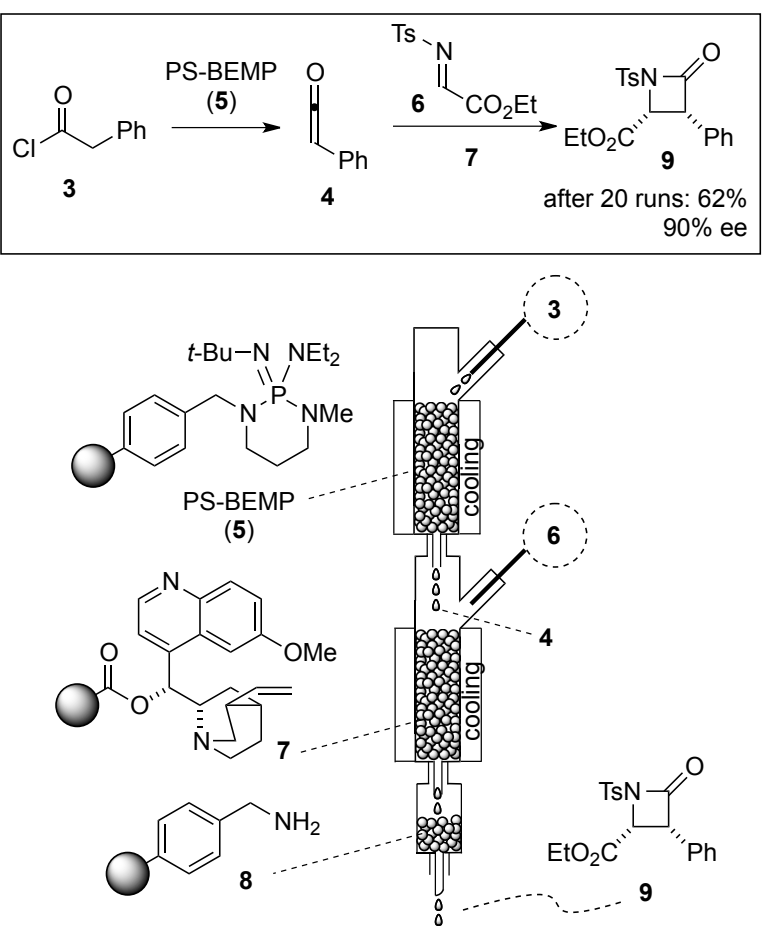

Scheme 2. Preparation of enantioenriched $\beta$-lactams 9 in flow.

Rather than being just a curiosity, performing this reaction in what the authors call "sequential column asymmetric catalysis", ${ }^{[23]}$ entailed a series of unique advantages that the usual flask chemistry could not parallel. Under these conditions, the unstable ketene was generated and immediately reacted, thus minimizing possible side reactions. Moreover, the basic resin $\mathbf{5}$ was found to destroy the imine and epimerize the final product, which cannot happen with this set-up. The introduction of spatial separation while minimizing the temporal one effectively killed two birds with one stone.

In a further effort, Lectka et al. described an alternative array that allowed generation of both reactive intermediates (4 and 6) in parallel, using two different columns (Scheme 3). The extra column was packed with a $6: 1(\mathrm{w} / \mathrm{w})$ mixture of $\mathrm{NaH}$ and Celite (10), which allowed to transform a chloroglycine derivative 11 into the corresponding imine ${ }^{[24]}$ The effluents of this column were combined with those of the PS-BEMP column and then the catalytic reaction was performed in the way described above, demonstrating the flexibility of this system. One of the main advantages of both systems is their robustness. After regeneration of the stoichiometric solid-supported reagents the reaction could be run for at least 60 times with the same column assembly, a truly impressive feat. 


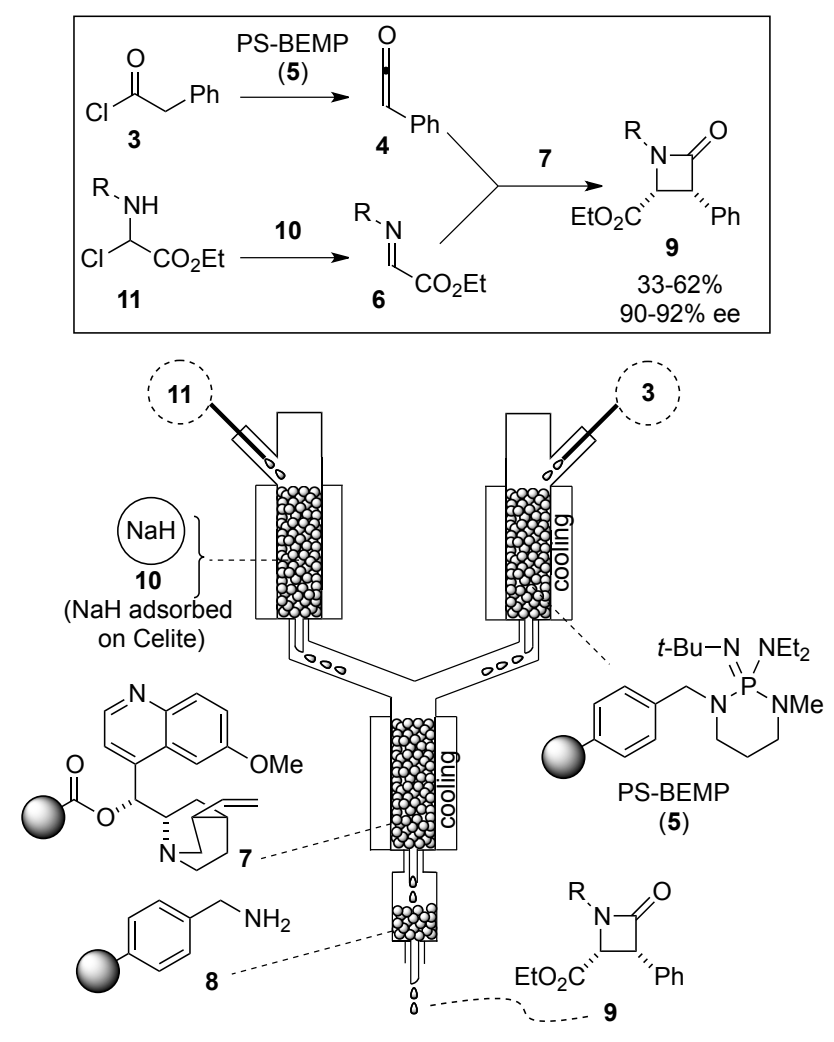

Scheme 3. Second assembly for the preparation of enantioenriched $\beta$-lactams 9 in flow.

After this, the authors managed to design yet another alternative reaction set-up that turned out to be the simplest (Scheme 4). This approach was based on a previous report from the same group, ${ }^{[25]}$ where ketenes were generated from the corresponding acyl chlorides by treatment with catalytic amounts of an amine (acting as a dehydrohalogenating agent) and finely meshed $\mathrm{K}_{2} \mathrm{CO}_{3}$ as a stoichiometric base. The underlying idea was to test whether the quinine derivative 7 could play a catalytic role in both the ketene formation and the $\beta$ lactam generation. Thus, a single column was packed with a mixture of finely powdered $\mathrm{K}_{2} \mathrm{CO}_{3}$ and 7 . Remarkably, the reaction took place smoothly under these conditions, albeit the results were not as good as in the previous cases $(61 \%$ yield, $7: 1 d r, 91 \%$ ee $) .{ }^{[2]}$ However, considering that upon recrystallization the product was obtained as a single enantiomer it is debatable whether the slightly better results justify the more complex (and expensive) multiple column array.

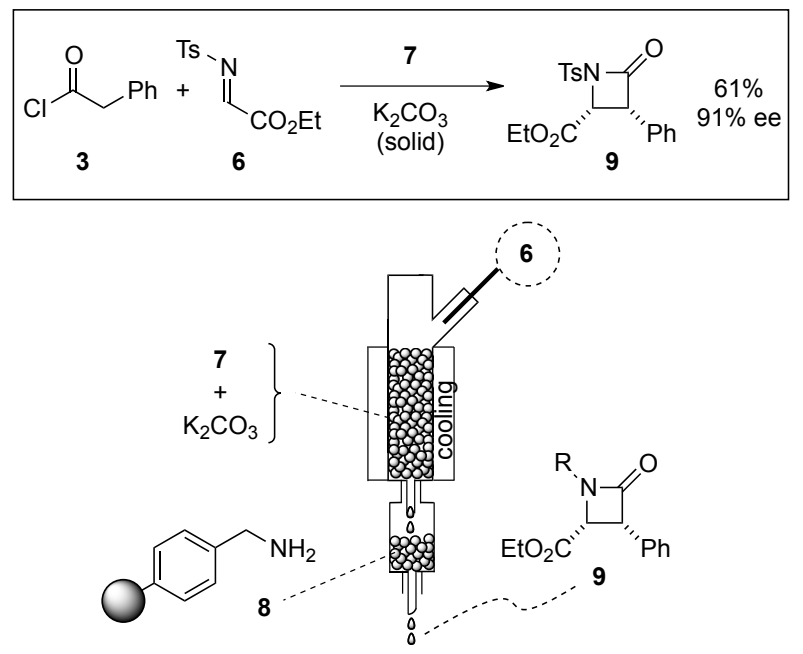

Scheme 4. Third and simpler set-up for the synthesis of $\beta$-lactams 9 in flow. 
A few years later, the same group published two closely related contributions based on their previous reports ${ }^{[26]}$ on the $\alpha$-chlorination of acyl chlorides mediated by Cinchona alkaloids. This time, 7 played a double role by acting both as a stoichiometric dehydrohalogenating agent and as the enantioselective nucleophilic catalyst for enolate formation from the corresponding acyl chloride. This strategy was applied in a "flush-andflow" system that, due to the fact that one equivalent of $\mathbf{7}$ is used in the reaction, had to be regenerated after each cycle by washing with a tertiary amine. ${ }^{[27]}$ Shortly after, the authors applied this column to a multi-step flow synthesis that allowed for the fully automated preparation of a complex peptide. ${ }^{[28]}$ Given the fact that the process was not truly catalytic it will not be discussed further, but it serves as a good example of the potential of packed bed reactors in asymmetric, multi-step continuous flow synthesis.

These pioneering works by Lectka et al. established a proof of concept, showing the potential of immobilized organocatalysts for performing asymmetric reactions in continuous flow. However, an important drawback of the method was the fact that it relied on gravity or pressure-driven flow, which makes results more difficult to reproduce since the dripping rate is not easily replicated in two different runs. This probably accounts for the fact that the rest of examples described in this review make use of pumps to force the fluid through the system (usually against gravity), while exerting a more accurate control over the flow rate.

\subsection{Cinchonidine derivative-catalyzed Michael reaction}

Taking a different approach, Hodge et al. also managed to immobilize a Cinchona alkaloid onto a polystyrenebased resin. This time, however, Cinchonidine was directly linked to a thiol-decorated polymer via thiol-ene click reaction to afford $12{ }^{[29]}$ This resin would be used as a chiral base catalyst to promote the Michael addition of 1-oxo-indan-2-carboxylate (13) to methyl vinyl ketone (14).

The experimental set-up to perform the reaction under flow conditions consisted in a closed glass tube $(360 \times 14 \mathrm{~mm})$ filled with resin $12\left(14.0 \mathrm{mmol}, 0.094 \mathrm{mmol} \cdot \mathrm{g}^{-1}\right)$ and immersed in a $50{ }^{\circ} \mathrm{C}$ water bath. The reagents were independently fed by the aid of two peristaltic pumps and two long needles were used to ensure that they reached the bottom of the packed bed reactor, where they first entered in contact with 12. Then, 13 and 14 slowly moved up the system and, at the top end, the solution with the reacted mixture was collected and removed from the system with a third peristaltic pump (Scheme 5). Under these conditions, the experiment was run for $72 \mathrm{~h}$ at a flow rate of $0.085 \mathrm{~mL} \cdot \mathrm{min}^{-1}$. This gave rise to $2.30 \mathrm{mmol}$ of product in almost quantitative yield. However, ee's were only moderate $(51 \%)$ and the overall process entailed superstoichiometric amounts of the catalytic resin 12 with respect to the reagents.

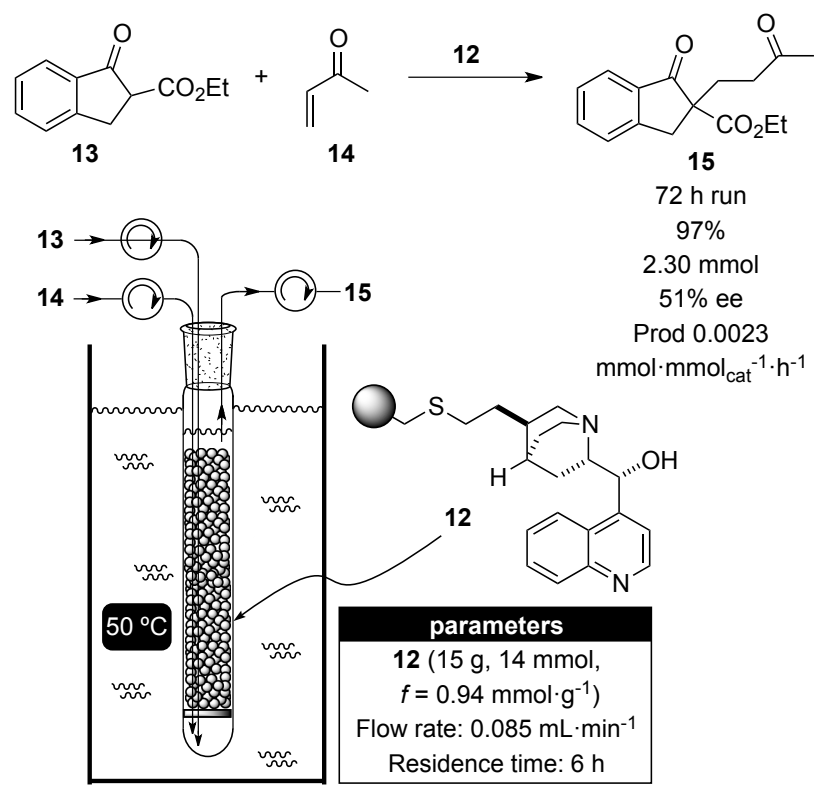

Scheme 5. Michael addition in flow catalyzed by PS-Cinchonidine 12

\section{Continuous Flow Reactions with Immobilized Aminocatalysts}




\subsection{Proline, pyrrolidine derivatives and amino acids}

Proline is one of the first molecules that comes to a chemist's mind when the word 'organocatalysis' is spoken. ${ }^{[30]}$ Plenty of other catalysts have been developed and reached success levels as high (and even higher) as this cyclic amino acid, but the fact that an apparently innocent molecule kept so many surprises in terms of reactivity and selectivity is a combination difficult to match. This motivated a number of research groups to embark in the immobilization of proline onto solid supports. ${ }^{[11 \mathrm{~d}]}$ Despite the affordability of this compound, this strategy was desirable for many reasons. For instance, it would facilitate product purification, a non trivial task given the relatively high catalyst loadings employed. In addition, taking into consideration that the products derived from aminocatalysis are carbonyl compounds themselves (and thus potentially capable of condensing with the catalyst), the continuous removal of reacted species from the media should minimize the possibility of product inhibition.

The proof of concept arrived in 2009 from the Pericàs laboratory, in a report that constitutes the first example of enamine activation with an immobilized catalyst in flow. Proline derivative 16a, anchored to a Merrifield-type resin via copper-catalyzed azide-alkyne cycloaddition ${ }^{[31],[32]}$ (CuAAC), had been previously reported by the same group to promote the enantioselective aldol reaction in batch ${ }^{[33]}$ After that, resin 16a was applied to the organocatalytic Mannich reaction ${ }^{[34]}$ of carbonyl compounds to glyoxylate imines ${ }^{[35]} \mathbf{1 7}$ in batch as shown in Scheme 6.

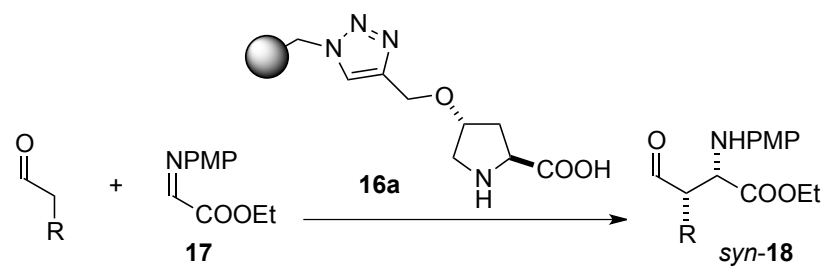

Scheme 6. Mannich reaction catalyzed by a polystyrene-supported proline.

In contrast to the case of the aldol reaction, the authors realized that the Mannich was quite fast. In consequence, the continuous flow addition of enolizable aldehydes to 17 was attempted in a simple set-up (a single pump was required, since the reagents were compatible in the absence of catalyst). The system consisted of two feeding flasks, one pump and an Omnifit column filled with 16a, as the packed-bed reactor. The first flask was full of DMF for the nonreaction operations such as swelling the resin at the beginning and rinsing the column at the end. The second flask contained a solution of the aldehyde and 17 in DMF, which was fed into the column when required (Figure 2).

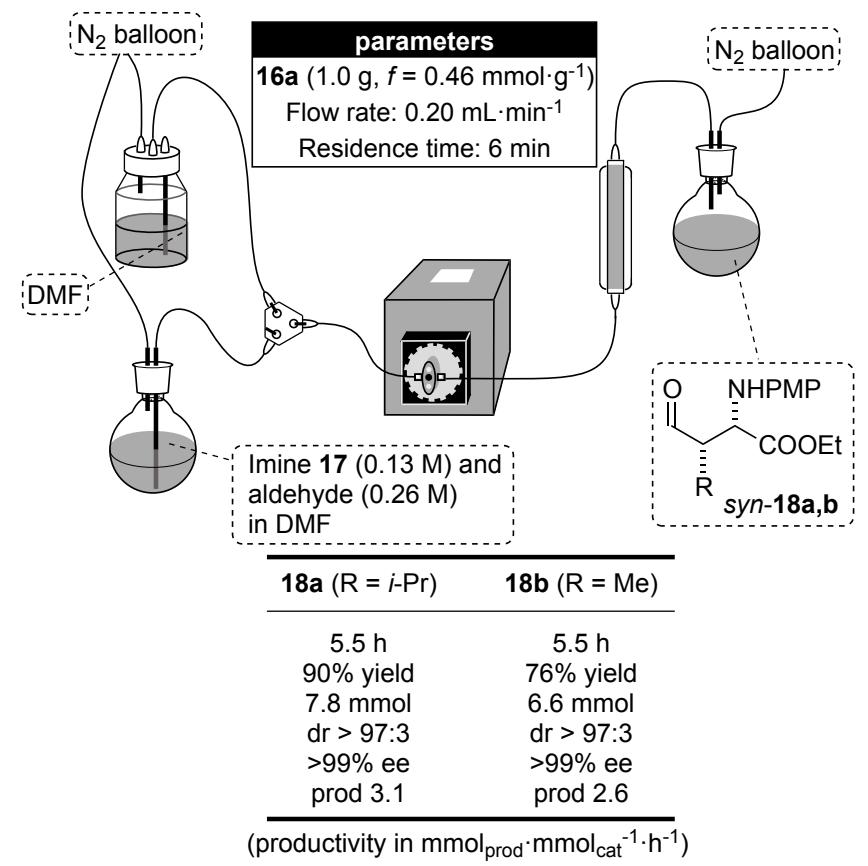

Figure 2. Set-up for the continuous flow Mannich reaction and results obtained with isovaleraldehyde and propanal. 
At the end of the system the outstream was collected and, due to the volatility of the aldehydes employed, a simple aqueous work-up to remove DMF provided the pure products. Two different aldehydes (isovaleraldehyde and propanal) were studied and in both cases the Mannich adducts 18a,b were obtained in very good yields and ee's. The numbers of the process confirmed the abovementioned hypotheses: indeed, the use of flow conditions avoided product inhibition, leading to full conversions in only 6 min residence time and allowing to decrease the overall catalyst loading four times with respect to the batch process. ${ }^{[35]}$

Shortly after, this group published a study that aimed to expand the scope of $16 \mathbf{a}$ and, at the same time, assess the impact of the degree of cross-linking of the polymeric matrix on the flow process. This parameter, given in percentage of divinylbenzene (DVB) added to the polymerization mixture, tends to be overlooked, although it is known to modulate at least two factors: the ability of the resin to swell and the size of the pore. ${ }^{[36]}$ Indeed, resins with low cross-linking degrees (tipically 1-4\%) are considered microporous, which means that they form a gel with some solvents and they have a high swelling ability. On the downside, they are more likely to collapse under high pressures, a situation likely to arise under flow conditions. On the other hand, macroporous resins (those having $>30 \%$ DVB) have much lower swelling properties but they display increased resistance towards mechanical collapse. This report was focused on establishing what happened in the neutral area between the two paradigmatic situations. Thus, two different polystyrene resins, closely related to $\mathbf{1 6 a}$ were prepared: $\mathbf{1 6} \mathbf{b}$, derived from a commercially available Merrifield resin (1\% DVB) and $16 \mathbf{c},{ }^{[37]}$ stemming from chloromethylpolystyrene with $8 \%$ DVB (Figure 3).

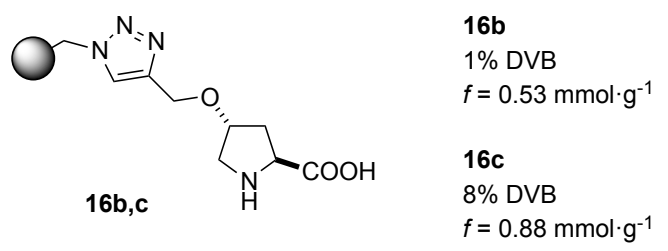

Figure 3. Polystyrene-supported proline derivatives $16 \mathrm{~b}, \mathrm{c}$ having different degrees of cross-linking

As expected, 16c was still swollen upon contact with organic solvents, but much less than $16 \mathrm{~b}$. The catalytic performance of both resins under flow conditions was examined with the $\alpha$-aminoxylation of five different aldehydes with nitrosobenzene. ${ }^{[38]}$ This time, given the existence of a background (non-catalyzed) reaction between the aldehydes and the nitroso derivative, the reagents had to be pumped independently and mixed immediately before the column packed with 16b,c (Scheme 7a). Thus, the experimental set-up was somewhat more complex than in the case of the Mannich reaction.

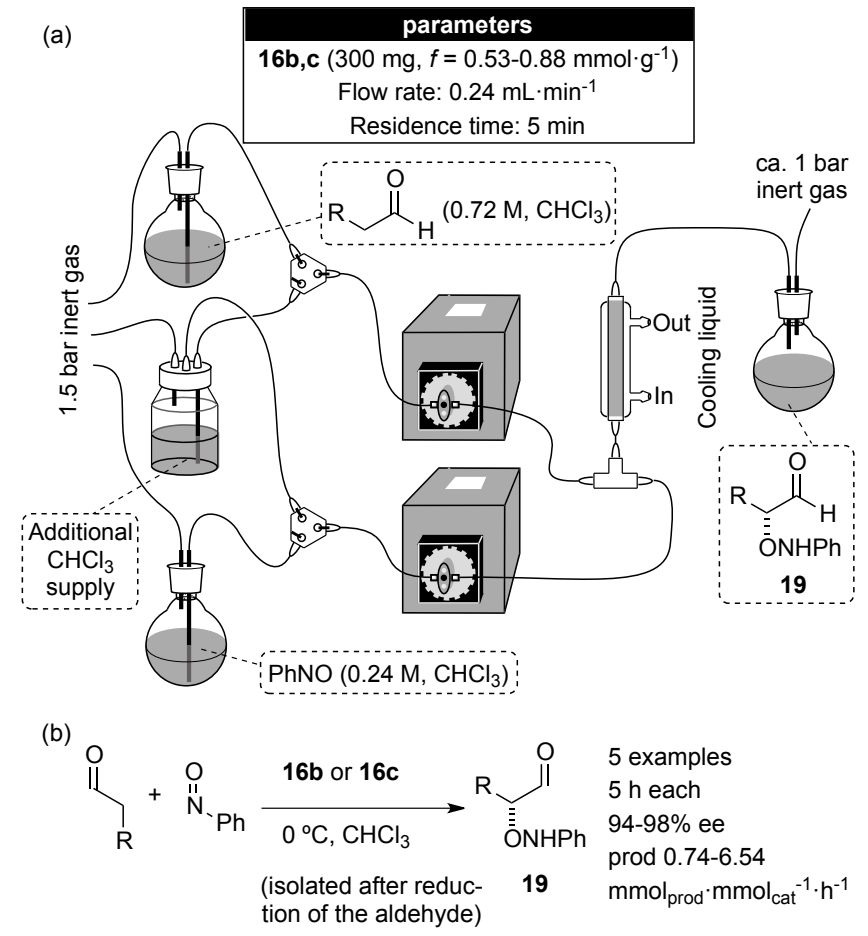

Scheme 7. (a) Set-up for the continuous flow $\alpha$-aminoxylation reaction and (b) results obtained with five different aldehydes. 
As far as the catalytic profile is concerned, the resins proved to behave very similarly, which seems to indicate that, as long as they swell, their behavior will not differ significantly. In other words, the degree of cross-linking was not an important parameter, at least below $10 \%$ DVB. However, the columns packed with resins 16 b,c turned out to lose activity upon prolonged use in this particular process. The drop was not sharp and it did not affect the enantioselectivity of the process, but after $5 \mathrm{~h}$ a $15-20 \%$ decrease in conversion could be observed when operating the system at a constant flow rate. Considering that this decrease in activity took place regardless of the degree of cross-linking of the resins, an explanation involving the degradation of the catalytically active species or the formation of a parasitic intermediate between this and one of the reactants seemed more reasonable than the mechanical collapse of $16 \mathbf{b}, \mathbf{c}$.

In 2011, Massi and co-workers studied the anchoring of proline derivatives in an alternative support such as silica. To this end they followed two different strategies to establish the most convenient approach in terms of lifespan, catalytic activity and selectivity. ${ }^{[39]}$ On the one hand, $16 \mathrm{~d}$ was prepared by covalent immobilization of a proline derivative via thiol-ene click reaction. On the other hand, they prepared silica with appended sulfonic acid groups to immobilize a pyrrolidine-derived diamine via ion pair formation: 16e (Figure 4).

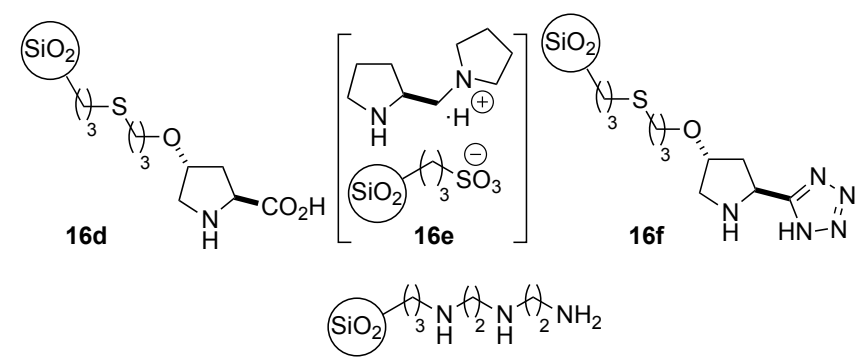

20

Figure 4. Silica-supported proline derivatives $16 \mathrm{~d}-\mathbf{f}$ and scavenger 20.

Thus, two HPLC-like columns were respectively filled with $16 \mathrm{~d}$ and $16 \mathrm{e}$ and the two reactors were employed in the aldol reaction between cyclohexanone and $p$-nitrobenzaldehyde. The outstream was passed through a column with triamine-functionalized silica $\mathbf{2 0}$, which played the role of scavenger for unreacted $p$ nitrobenzaldehyde.

With silica $16 \mathrm{~d}$, albeit the flow rate was relatively low $\left(5 \mu \mathrm{L} \cdot \mathrm{min}^{-1}\right.$, for a residence time of $\left.32 \mathrm{~min}\right)$, the conversion was $60 \%$ in the steady state. As for the stereoselectivities, the values obtained for 21 a matched those of the batch procedure $(4: 1 d r, 78 \%$ ee, Figure 5$)$. The system proved stable for at least $24 \mathrm{~h}$ under these conditions. After that, a slow decay of conversion was noticed (stereoselectivities remained constant) until the total deactivation after $72 \mathrm{~h}$. The effect of the temperature was also evaluated; as expected, at $0{ }^{\circ} \mathrm{C}$ the enantioselectivity was improved to $82 \%$, but at the expense of lowering the conversion to $38 \%$. On the other hand, when the system was warmed to $50{ }^{\circ} \mathrm{C}$ the conversion increased to $82 \%$ without erosion of enantioselectivity. Finally, further heating to $70^{\circ} \mathrm{C}$ resulted in decomposition of the mixture, thus indicating that the range of temperatures is rather narrow. As for $16 \mathbf{e}$, immobilized via ionic interactions, it displayed a much poorer catalytic profile, and showed very limited stability. Indeed, after a flow experiment of $2 \mathrm{~h}$ the chiral amine was completely leached from the solid-support.

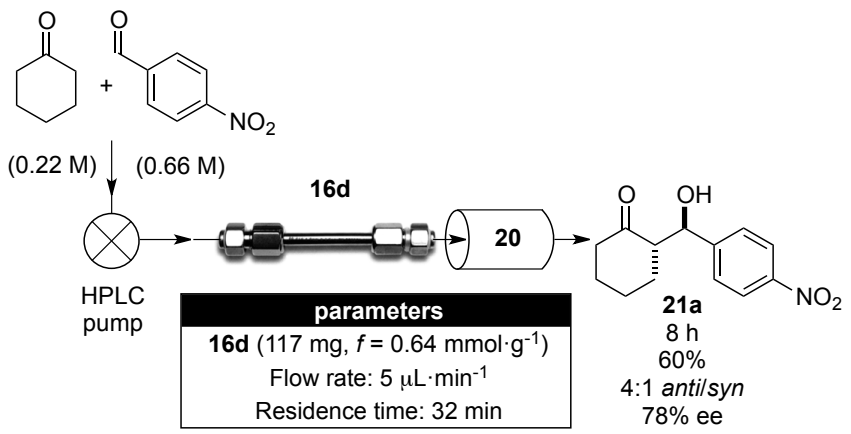

Figure 5. Continuous flow aldol reaction catalyzed by silica-supported proline derivative $\mathbf{1 6 d}$ 
To further expand the scope of the functionalized silica 16d, the authors implemented the continuous flow $\alpha$ amination of aldehydes with azodicarboxylates. ${ }^{[39]}$ Compared to the aldol reaction, this transformation allowed working at much higher flow rates (full conversion at $75 \mu \mathrm{L} \cdot \mathrm{min}^{-1}$ ), but the enantioselectivities recorded for 22 $(58 \%$ ee) were significantly lower than those observed in batch (Figure 6$)$.

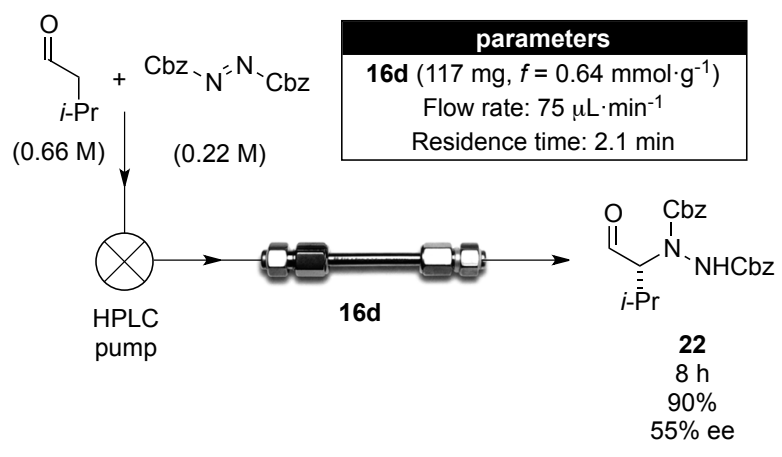

Figure 6. Continuous flow $\alpha$-amination of aldehydes catalyzed by silica-supported proline derivative $\mathbf{1 6 d}$.

In their report, Massi et al. raise an important point when comparing two of the most common solid phases used for heterogenization of chemicals: polystyrene ${ }^{[12 c]}$ and silica. ${ }^{[12 a, b]}$ While the former presents lower mechanical stability, especially at elevated pressures, the latter shows differential retention of the chemical species. This feature, albeit very useful for most chromatographic procedures, severely hampers the proper choice of stoichiometry, since the conditions optimized in batch might not be suitable in flow. It is the task of chemists to decide which of the drawbacks might be more important and which is going to be irrelevant in each process.

Later on, these authors reported the use of $\mathbf{1 6 f}$ (Figure 4) to promote the aldol reaction. ${ }^{[40]}$ With this tetrazolesubstituted catalyst, nearly quantitative yields could be obtained at $5 \mu \mathrm{L} \cdot \mathrm{min}^{-1}$ and $50{ }^{\circ} \mathrm{C}$. The system proved very robust and only after $120 \mathrm{~h}$ a progressive loss of catalytic activity could be detected.

In 2011, Sels and co-workers published a report where an alternative immobilization strategy was tested. Instead of establishing a covalent link between the catalyst and the solid support, they relied on the formation of a salt between a strong acid and a diamine. This approach, while similar to Massi's 16e, proved much more successful, as the authors screened several combinations of solid acids and aminocatalysts until they found the right choice. The advantage of this method lies in the fact that the catalytically active species can be used without much derivatization; however, preliminary studies need to be done to ensure that the solid phase does not interfere with the reaction. Thus, Sels et al. found the catalytic pair Nafion NR50/23 to give the best results in batch. Then, they reported the catalytic continuous flow addition of butanone to $p$ trifluoromethylbenzaldehyde, which took place with good conversions and ee's at the beginning of the process, although the activity decayed somewhat after 6 hours $^{[41]}$ (Scheme 8). 

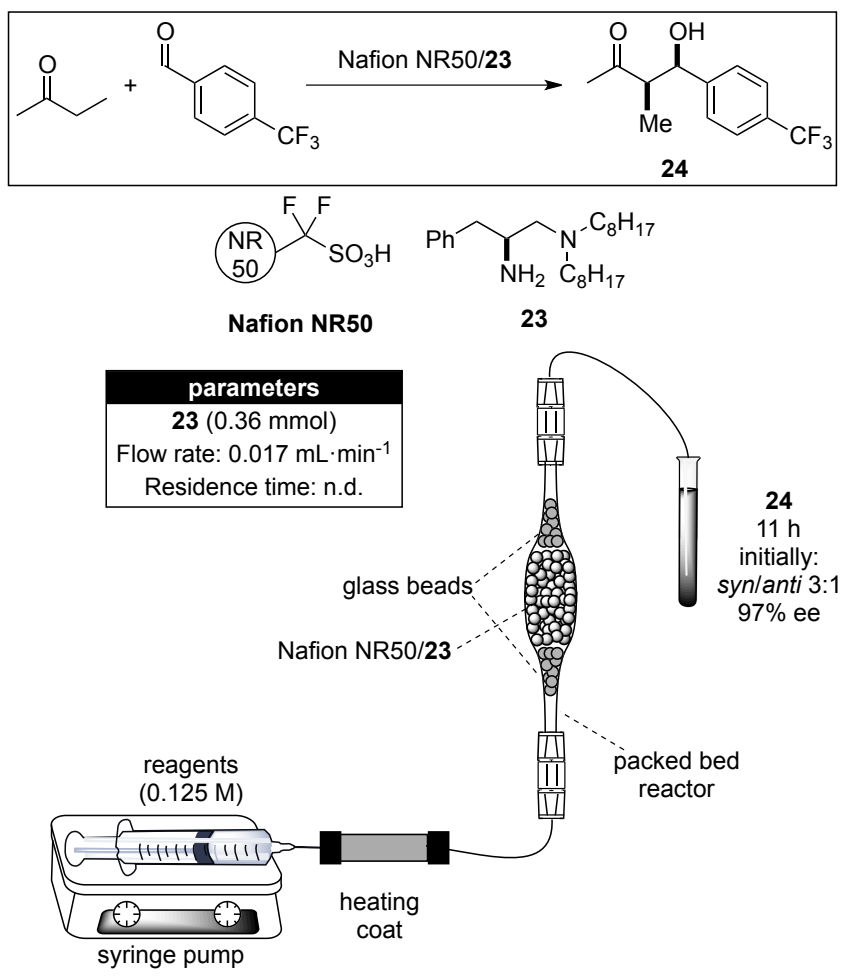

Scheme 8. Use of the catalytic pair Nafion NR 50/23 in the catalytic aldol reaction in flow.

In 2012, and based on the abovementioned proline derivatives 16a-c, Pericàs et al. developed 16g. The introduction of a spacer was aimed at drawing the catalytically active species away from the polystyrene chain, in an attempt to improve the mass transfer and accelerate the reaction. With this approach, a highly enantioselective continuous flow aldol reaction could be implemented. The resin $\mathbf{1 6 g}$ turned out to be very robust, as demonstrated by the fact that an experiment with $p$-nitrobenzaldehyde could be running for $45 \mathrm{~h}$ at $25 \mu \mathrm{L} \cdot \mathrm{min}^{-1} .{ }^{[42]}$ To further prove the versatility of this approach, the authors prepared four different analogues in a sequential manner. This was done by simply feeding the system with a mixture of cyclohexanone and the corresponding aldehyde for $8 \mathrm{~h}$, then rinsing with solvent and feeding the next combination. As shown in Scheme 9 , the stereoselectivities recorded were very high, albeit the flow rates could not be higher than 25 $\mu \mathrm{L} \cdot \mathrm{min}^{-1}$.
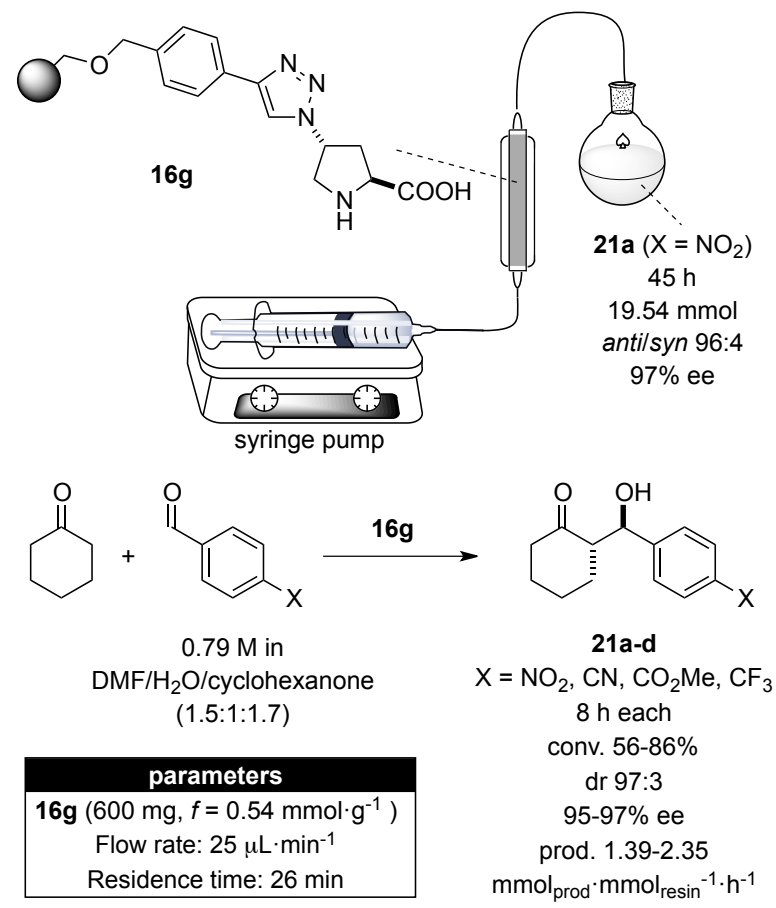
More recently, the same group has published the preparation of $\mathbf{2 5}$, a pyrrolidine derivative functionalized at $\mathrm{C}_{3}$ and $\mathrm{C}_{4} \cdot{ }^{[43]}$ The goal behind this was to switch the usual syn-selectivity obtained in the proline-catalyzed Mannich reaction to the trans product, with a design based in the work of Barbas ${ }^{[44]}$ and Blanchet. ${ }^{[45]}$ The versatility of the system was demonstrated with a series of flow experiments that employed four different aldehydes and three ketones. ${ }^{[46]}$ In some cases, the catalytic resin $\mathbf{2 5}$ proved so robust that the flow process was running for more than two days at flow rates of $0.2 \mathrm{~mL} \cdot \mathrm{min}^{-1}$. Using only $500 \mathrm{mg}$ of resin, the conversion in this remarkably long experiment was $97 \%$, with TONs approaching 300 ; overall, more than $68 \mathrm{mmol}$ of anti18 could be produced in a single experiment. In addition, the combination of volatile reagents and solvents allowed obtaining pure products after a simple evaporation of the outstream (Scheme 10).

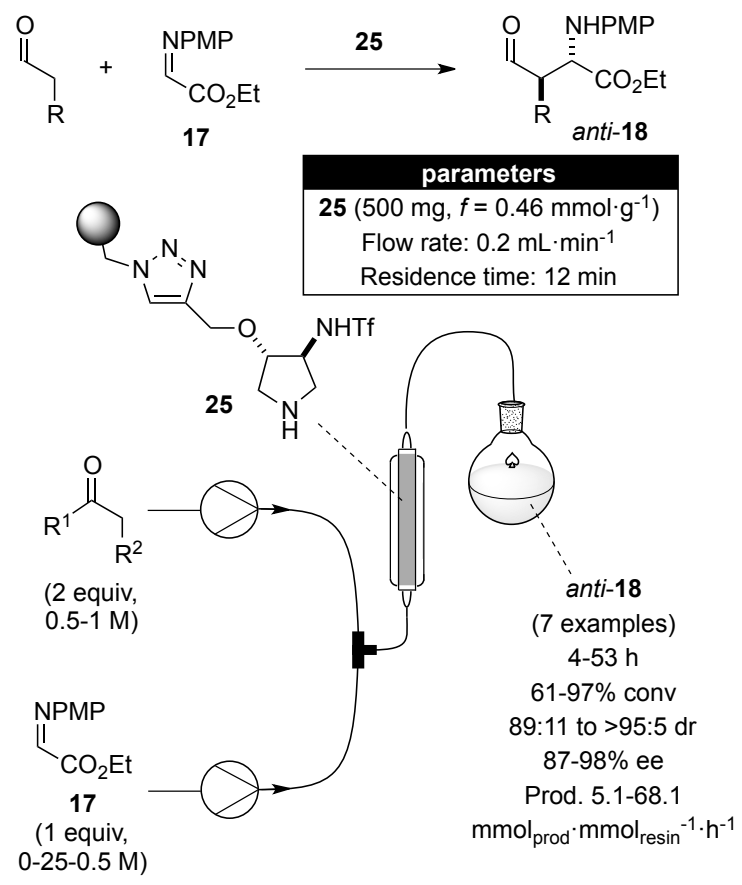

Scheme 10. Supported pyrrolidine $\mathbf{2 5}$ as a catalyst for the anti-selective Mannich reaction in flow.

Very recently, the same group has reported the three-component Mannich reaction with 26, a threonine derivative anchored to polystyrene using a click strategy. In contrast to proline, primary amino acids are known to give rise to the anti-Mannich product 27. ${ }^{[4]}$ The authors have shown two applications in continuous flow (Scheme 11), as well as the generation of a small library of analogues, using $26 .{ }^{[48]}$ Remarkably, this time preformation of the imine was not required so this can be considered as a three-component flow process. 


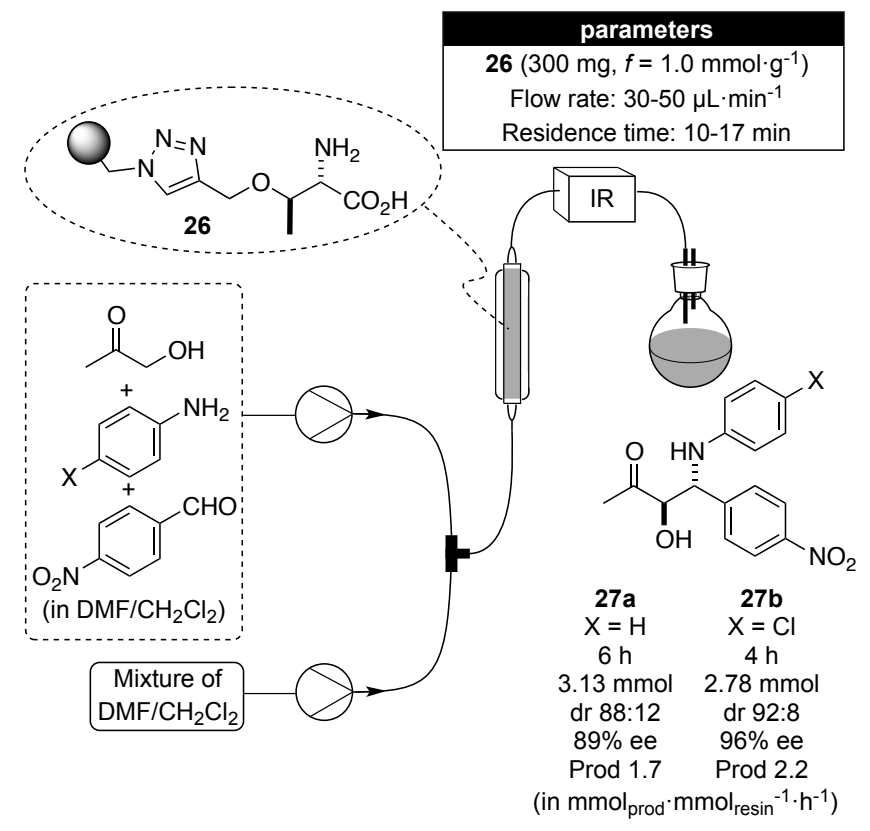

Scheme 11. Supported primary amino acid $\mathbf{2 6}$ as a catalyst for the anti-selective, three-component Mannich reaction.

\subsection{Supported Diarylprolinol Derivatives}

Diarylprolinol derivatives, developed at the same time by Jørgensen ${ }^{[49]}$ and Hayashi, ${ }^{[50]}$ constitute one of the most versatile classes of aminocatalysts due to the fact that they excel in both the enamine and iminium ion activation modes. ${ }^{[51]}$ Thus, it is not surprising that several groups have embarked in their immobilization onto a solid support. ${ }^{[52]}$ However, despite these examples, applications of immobilized diarylprolinol derivatives in continuous flow are scarce. The first one dates from 2011, when Pericàs et al. reported a flow cascade process $^{[53]}$ catalyzed by the trimethylsilyl protected diphenylprolinol derivative $\mathbf{2 8 a} \mathbf{a}^{[54]}$ anchored to polystyrene employing the triazole strategy described above. The domino reaction was a Michael-Knoevenagel sequence that took place between oxoglutarate 29 and $\alpha, \beta$-unsaturated aldehydes, ${ }^{[5]}$ giving rise to the cyclic intermediate 30; upon reductive treatment with $\mathrm{NaBH}_{4}$, this provided the cyclohexane derivative 31 containing four stereocenters (Scheme 12).

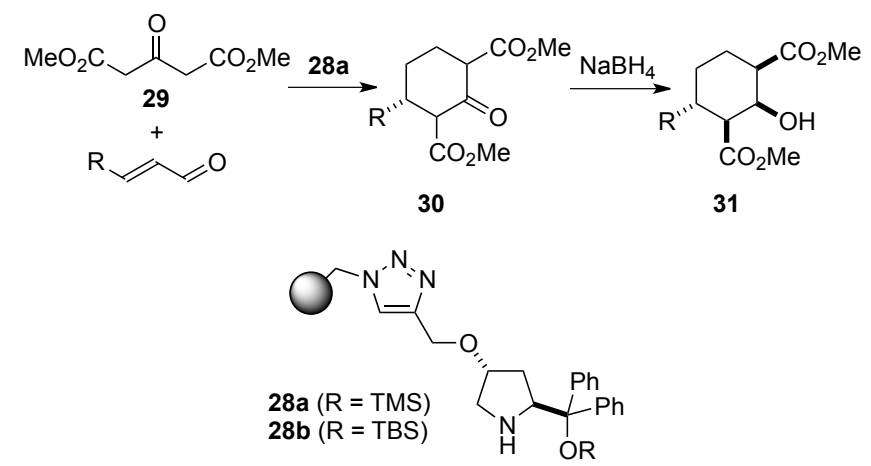

Scheme 12. Michael-Knoevenagel cascade process catalyzed by $\mathbf{2 8 a}$.

Feeding a mixture of the two reagents with benzoic acid (needed as a co-catalyst) at $0.12 \mathrm{~mL} \cdot \mathrm{min}^{-1}$ allowed reaching conversions of $60-65 \%$ (Figure 7). However, the most remarkable fact is that these were maintained during a 3-day flow process in which the stereoselectivity was also kept constant at excellent levels $(97 \%$ ee). 


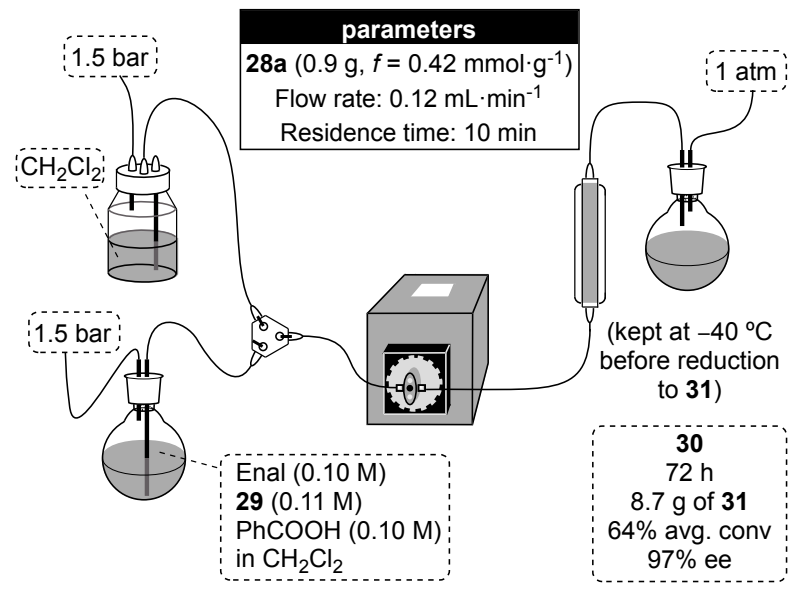

Figure 7. Set-up for the continuous flow asymmetric Michael-Knoevenagel sequence.

After this initial success with catalyst $\mathbf{2 8 a}$, the same group reported the implementation of the organocatalytic $\alpha$-amination of aldehydes ${ }^{[56]}$ in a continuous flow process. ${ }^{[57]}$ In this case, an unwanted side reaction was observed between the catalyst and the aminating agent dibenzylazodicarboxylate (DBAD). In batch this was solved by slow addition of the aldehyde, but this approach was not possible in flow. Thus, the authors were forced to use an excess of aldehyde to ensure that the catalyst would be more prone to enamine formation than to react with DBAD. Under these conditions, an experimental set-up with two independent pumps was assembled to carry out the flow process as depicted in Scheme 13.

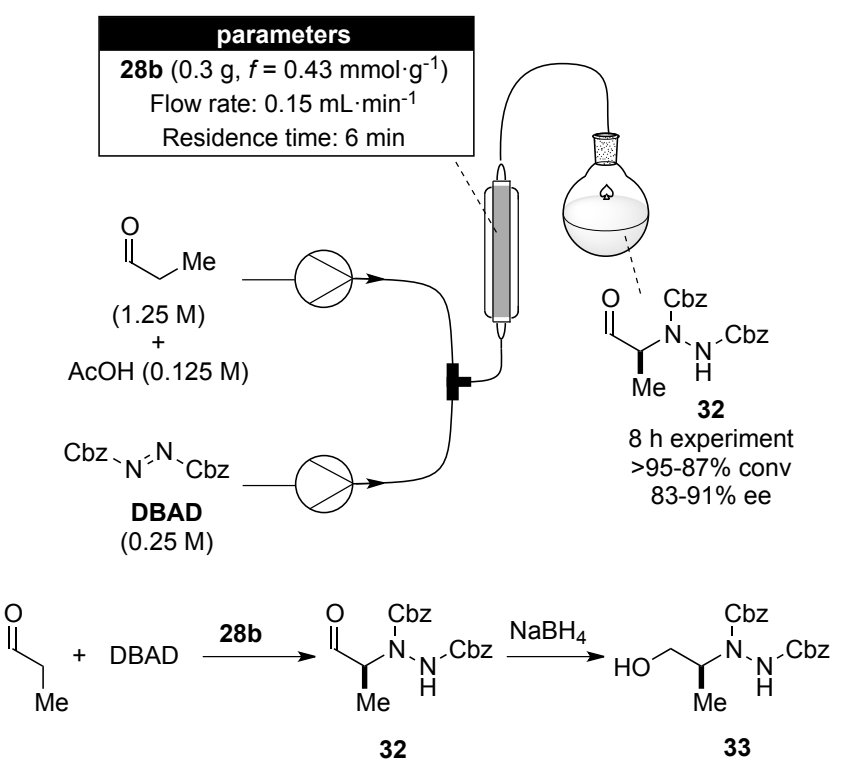

Scheme 13. Enantioselective $\alpha$-amination of aldehydes in flow.

The experiment was maintained for $8 \mathrm{~h}$ at a combined flow rate of $0.15 \mathrm{~mL} \cdot \mathrm{min}^{-1}$. The first 6 hours full conversions were recorded and after that a small decrease was detected. As for the enantioselectivities, the values were found to oscillate between $88-91 \%$ ee after initial stabilization. When the system was stopped after $8 \mathrm{~h}$ the instant conversion was $87 \%$, with $88 \%$ ee.

\subsection{Polystyrene-Supported Peptides as Catalysts}

Robert B. Merrifield received the Nobel prize in 1984 for his work on solid phase peptide synthesis (SPPS). ${ }^{[58]}$ Indeed, many of the strategies and applications shown above are based on the resins and the chemistry developed to this end. Therefore, some authors have identified the intermediates used in SPPS (i.e. peptides still linked to the resin) as valuable catalysts per se, without having to cleave them off the polymeric support. 
The first ones to apply such a supported synthetic peptide in flow were Fülöp and co-workers. Based on the work of Wennemers et al. with peptidic immobilized organocatalysts ${ }^{[59]}$ they chose the addition of aldehydes to nitroalkenes ${ }^{[60]}$ as the benchmark reaction. Then, a systematic study of the different parameters that can affect the performance of these peptidic catalysts in a flow apparatus was carried out. ${ }^{[61]}$ For instance, they tested different flow rates and they noticed an interesting trend: low flow rates were required for high conversions, but the consequently long residence times entailed lower stereoselectivities. As they found out, the catalyst was able to epimerize the final product, so they decided to work at $0.1 \mathrm{~mL} \cdot \mathrm{min}^{-1}$ as a compromise that provided both good yields and stereoselectivities. In addition, they also studied the effect of pressure. Interestingly, they observed a positive effect of high pressures (60 bar), after which they managed to demonstrate that the reaction is under diffusion control. Under the optimized reaction conditions, catalyst 34 (H-D-Pro-Pro-Asp-NH-resin) was shown to promote the reaction with a number of aldehydes (Figure 8). The corresponding Michael adducts $\mathbf{3 5}$ were generally obtained in good yields and excellent stereoselectivities.

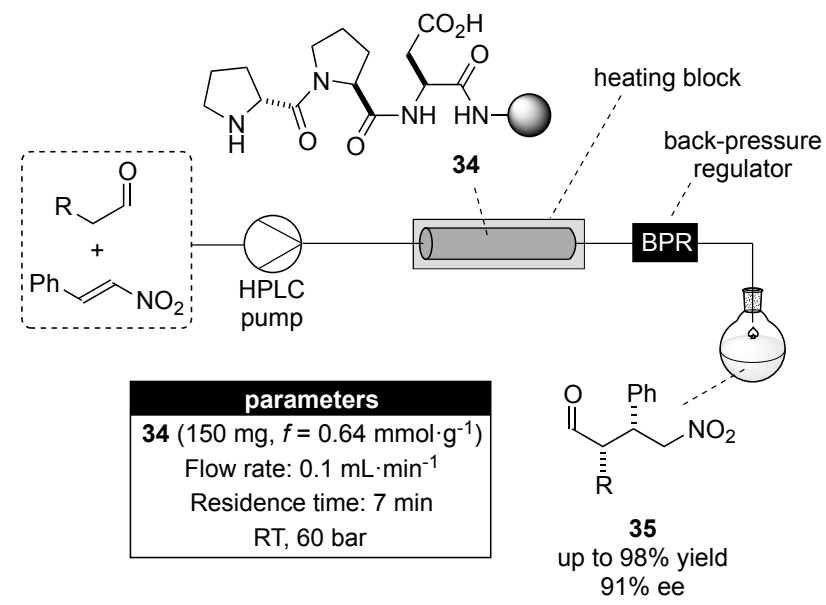

Figure 8. Use of the polystyrene-supported peptide $\mathbf{3 4}$ as a catalyst for the continuous flow Michael addition of aldehydes to nitroalkenes.

Shortly after, the same authors published a related study focused on the aldol reaction, ${ }^{[62]}$ demonstrating that the general trends identified in the previous example also applied in this case. However, catalyst screening advised the use of a different immobilized peptide (36). Thus, pumping a solution of the aldehyde in acetone (serving both as a pro-nucleophile and as the solvent) at $0.1 \mathrm{~mL} \cdot \mathrm{min}^{-1}$, Fülöp et al. were able to generate several aldol products in flow (Figure 9). As expected, aromatic aldehydes with electron-withdrawing groups worked better, but moderate to good enantioselectivities were obtained in all cases $(71-80 \%$ ee).

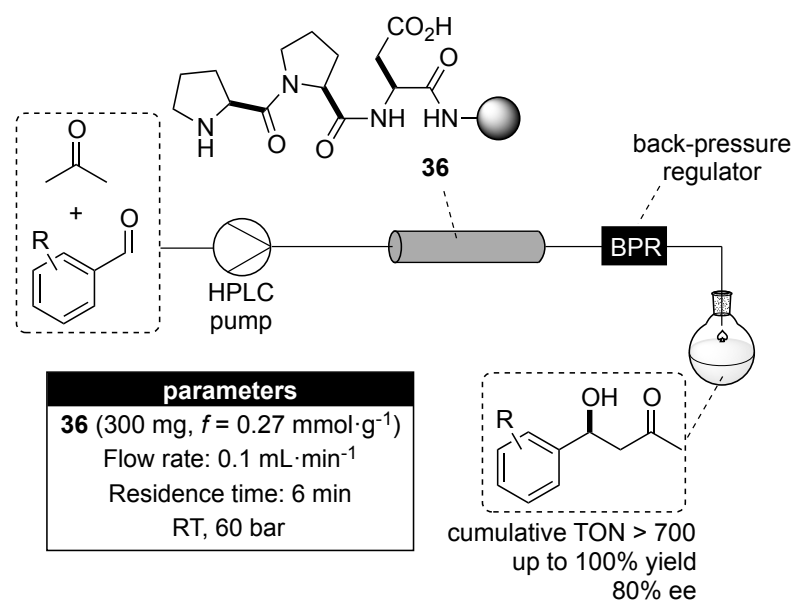

Figure 9. Enantioselective aldol reaction between acetone and aromatic aldehydes catalyzed by peptide 36 .

One year later, the group of Wennemers, well known for their studies with organocatalytic peptides, ${ }^{[59]}$ decided to implement a continuous flow process with resin-bound peptide $37 .{ }^{[63]}$ This catalyst was quite similar to 34 
but, after a comparative study, it was shown that the introduction of a long and flexible linker succeeded in separating the catalytically active unit from the polymer backbone. As a result the behavior of $\mathbf{3 7}$ was more similar to its homogeneous counterpart, thus providing better reaction rates and improving the stereoselectivities. Working at room temperature and with a flow rate of $0.23 \mathrm{~mL} \cdot \mathrm{min}^{-1}$, the packed bed reactor having $2.7 \mathrm{~g}$ of catalyst provided the desired product in excellent yields and enantioselectivities (Figure 10). Remarkably, since all the components of the mixture were volatile except for $\mathbf{3 5}$ and nitrostyrene, simple evaporation gave rise to a product with $95 \%$ chemical purity. A simple crystallization, allowed the isolation of more than $20 \mathrm{~g}$ of chemically and optically pure 35 . Moreover, 37 proved to be incredibly robust, since the initial $2.7 \mathrm{~g}$ were used intensively. After an accumulated TON of ca. 400, the authors run a few parallel reactivation tests and $\mathrm{Et}_{3} \mathrm{~N}$ washings were identified as a very convenient way of restoring a catalytic activity almost identical to the one observed for the freshly prepared 37 .
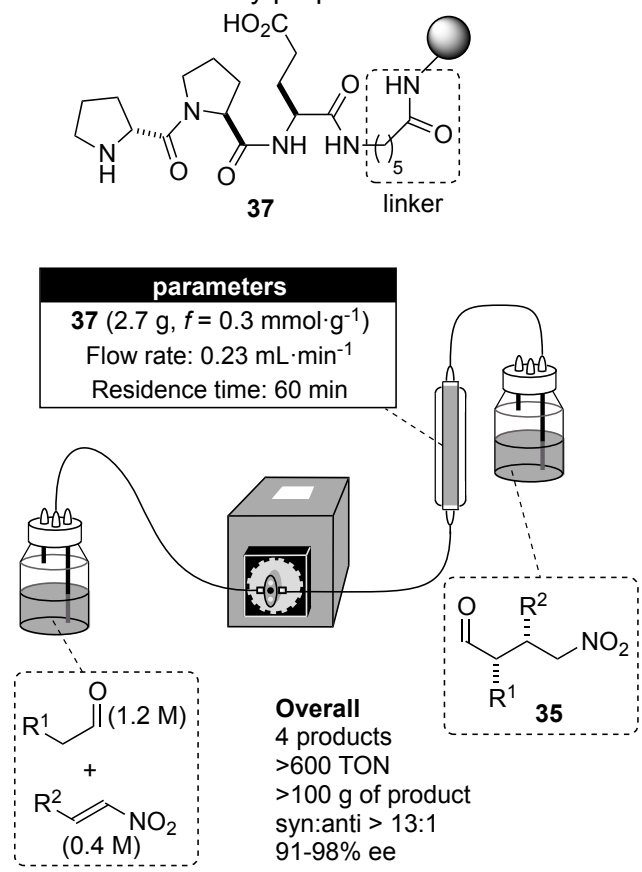

Figure 10. Michael reaction in flow catalyzed by peptide $\mathbf{3 7}$, bearing a longer linker than $\mathbf{3 4}$.

\subsection{Solid-Supported MacMillan Imidazolidinone Catalysts}

Recently, another secondary amine has joined the group of supported organocatalysts used in continuous flow: no less than the first generation MacMillan catalyst. These imidazolidinones were first introduced in the pioneering report that established the LUMO lowering effect of iminium ion formation as an extremely powerful and versatile tool for enantioselective catalysis. ${ }^{[64]}$ In an attempt to exploit their catalytic performance in flow, the group of Benaglia and Puglisi has studied its immobilization onto a variety of supports. First, they tested silica, preparing a 'home-made HPLC column' packed with $38 \mathrm{a}^{[65]}$ (Figure 11) that allowed for a continuous flow Diels-Alder reaction between cyclopentadiene and an $\alpha, \beta$-unsaturated aldehyde. The system was stable for long periods of time, but the slow catalytic turnover imposed very low flow rates. A similar report by the same group has expanded this previous work by comparing different methods for the preparation of the silicabased material, as well as different anchoring strategies to support the organocatalytic moiety ${ }^{[66]}$ (for instance, 38b, in Figure 11). Remarkably, the authors also demonstrated that the catalyst could be regenerated by washing with $\mathrm{HBF}_{4}$ in acetonitrile after the activity was found to decay. 


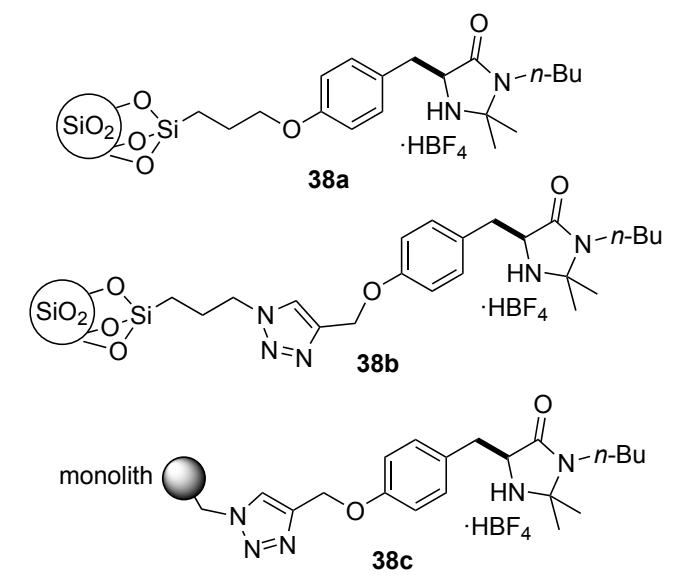

Figure 11. Immobilized MacMillan imidazolidinones 38.

Recently, this group has expanded the scope of supported MacMillan catalysts by evaluating the activity of a set of monoliths decorated with chiral imidazolidinones. As mentioned above, monolith ${ }^{[67]}$ are one of the three main classes of catalytic microreactors for supported species (together with packed bed and functionalized inner wall). Their main advantages are the low swellability and the large surface area within the polymeric matrix. With this goal in mind, Benaglia et al. prepared a MacMillan catalyst derivative following a click strategy introduced by Pericàs et al. ${ }^{[6]}$ Then, it was co-polymerized with divinylbenzene in the presence of dodecanol and toluene as porogenic agents, providing $38 \mathrm{c}$ as a monolith ${ }^{[69]}$ (Figure 11). This was then tested in the catalytic Diels-Alder reaction between cyclopentadiene and an $\alpha, \beta$-unsaturated aldehyde. ${ }^{[64]}$ Unfortunately, the reaction turned out to be rather slow, so the flow rates employed were ca. $2 \mu \mathrm{L} \cdot \mathrm{min}^{-1}$ (residence times $>12 \mathrm{~h}$ ). These could be increased somewhat by changing the counterion of the catalytically active species, which allowed to reach $18.8 \mu \mathrm{L} \cdot \mathrm{min}^{-1}$. However, despite the limitations imposed by these low flow rates, the monoliths still hold good promise, since they proved stable for periods up to $300 \mathrm{~h}$ (Figure 12). Moreover, they could be applied to other iminium ion mediated reactions.

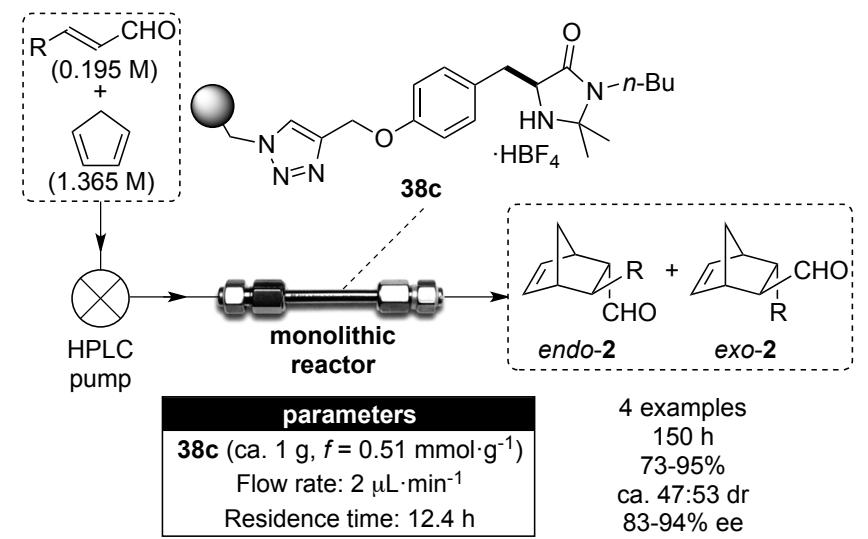

Figure 12. Polystyrene-based monolith $38 \mathrm{c}$ for enantioselective iminium ion activation in flow.

\section{Solid-Supported Brønsted Acid Catalysts in Flow}

Recent years have witnessed an increasing interest in the use of chiral Brønsted acids to promote enantioselective reactions by protonation of substrates with free electron pairs. ${ }^{[70]}$ For the purpose of this review we will also include in this category species acting via $\mathrm{H}$-bonding activation, ${ }^{[71]}$ given the fact that it is not always easy to differentiate between these two situations. ${ }^{[72]}$ To date, very few reports involving the use of solid-supported Brønsted acids in continuous flow have been published. Despite the scarcity of examples, these have shown great promise due to their extended lifespan when compared to aminocatalysts. This observation is likely ascribable to their different mechanism of action. Whereas primary and secondary amines require the formation of a covalent bond between the catalytically active species and the substrates, Brønsted acids rely solely on protonation. As a consequence, there are fewer pathways available for irreversible catalyst 
deactivation in the form of an off-cycle reaction that leads to a dead-end. With Brønsted acids, in the event of such a loss of activity, simple acid-base treatment might be sufficient to regain the initial performance.

\subsection{Polystyrene-Supported Bifunctional Squaramides}

Squaramides are extremely good $\mathrm{H}$-bond donors with very particular coordinating abilities. Thus, these exoticlooking compounds were first studied in molecular recognition, ${ }^{[73]}$ but lately they have attracted a lot of interest in enantioselective catalysis. ${ }^{[70 e, f]}$ Based on the groundbreaking work by Rawal, ${ }^{[74]}$ the Pericàs laboratory has developed an immobilized version of the successful bifunctional squaramides. First applied in batch, ${ }^{[7]}$ the polystyrene-based resin 39 allowed the implementation of a flow process involving the addition of hydroxynaphthoquinone $(\mathbf{4 0})$ to a series of nitroalkenes, ${ }^{[76]}$ as reported in homogeneous phase by Du and coworkers ${ }^{[77]}$ Given the high catalytic activity of 39 , the authors set up a packed bed reactor filled with only 250 $\mathrm{mg}$ of the catalytic resin. Under these conditions, feeding a mixture of the reagents at $0.2 \mathrm{~mL} \cdot \mathrm{min}^{-1}$, a flow experiment spanning $22 \mathrm{~h}$ took place (Figure 13). Even though the conversion experimented a slow decay it was still more than $60 \%$ at the end of the process. In turn, the enantioselectivity remained constant at $96 \%$ ee regardless of this loss of catalytic activity, the cumulative TON reaching 214.

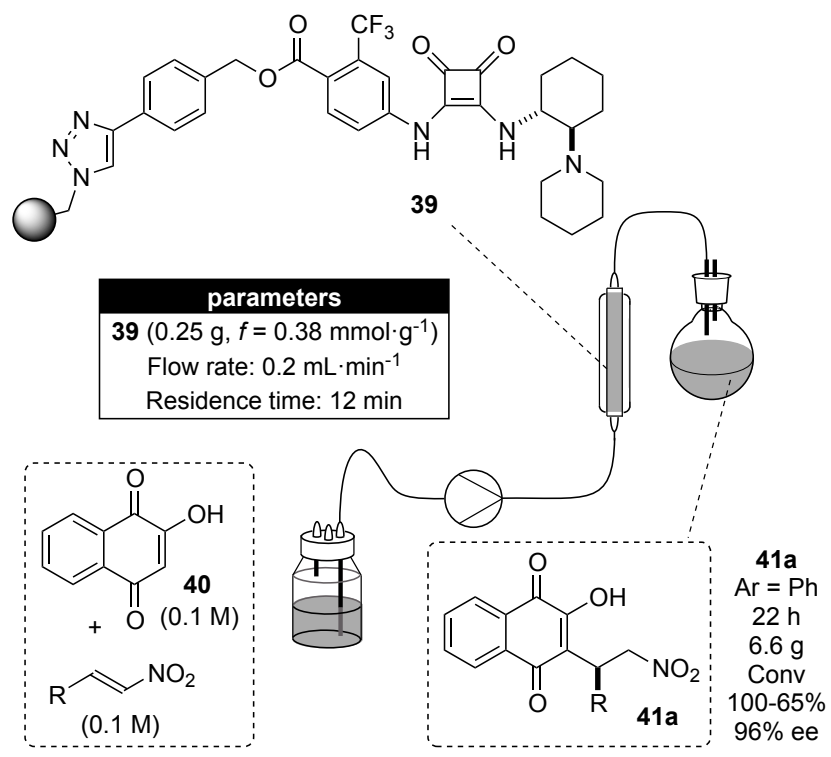

Figure 13. Squaramide resin $\mathbf{3 9}$ in the continuous flow addition of $\mathbf{4 0}$ to nitroalkenes.

To further demonstrate the versatility of the system, the synthesis of a small library of analogues was carried out in flow by (a) pumping a combination of substrates, (b) rinsing with solvent and (c) repeating the process with a different combination of starting materials (Figure 14). This approach allows for the fast production of libraries of enantiopure compounds with temporal separation, which can be seen as an alternative to combinatorial methods. To this end, and especially for big libraries, it would be especially interesting to carry out the automation ${ }^{[78]}$ of this method to prepare collections of compounds. 


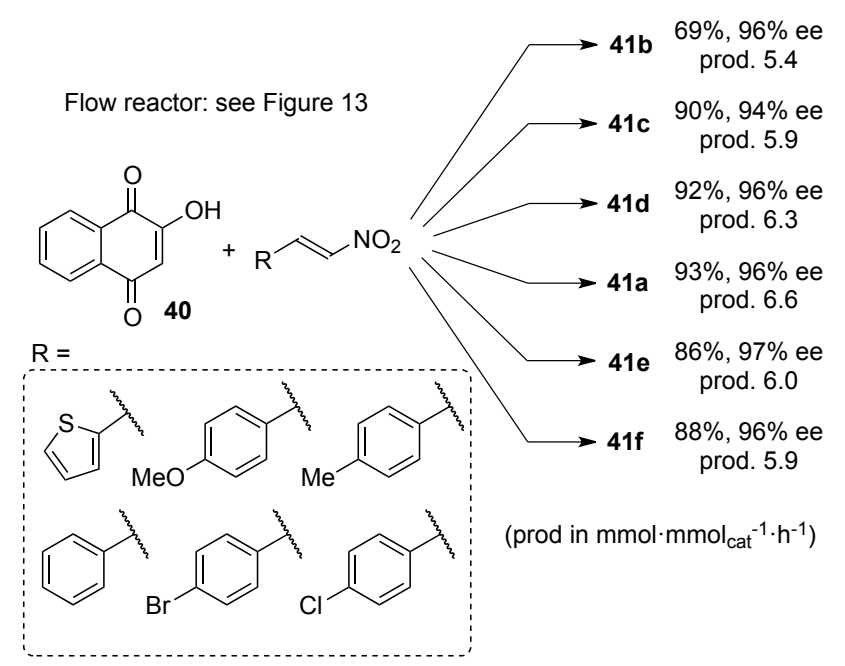

Figure 14. Use of 39 in the preparation of a small library of compounds in flow.

More or less at the same time, the group of Soós reported the preparation of 42, a tether-free, supported squaramide derived from a cinchona alkaloid. This catalyst was successfully applied in the continuous Michael addition of 1,3-dicarbonyl compounds to nitrostyrene, ${ }^{[79]}$ which could be running for $17 \mathrm{~h}$ without loss of catalytic activity (Figure 15). The two examples reported in flow gave rise to the corresponding Michael adducts in very good yields and excellent enantioselectivities. Interestingly, these two examples were run in a sequential manner so, as in the case shown in Figure 14, the authors mention process automation as a goal to be pursued.

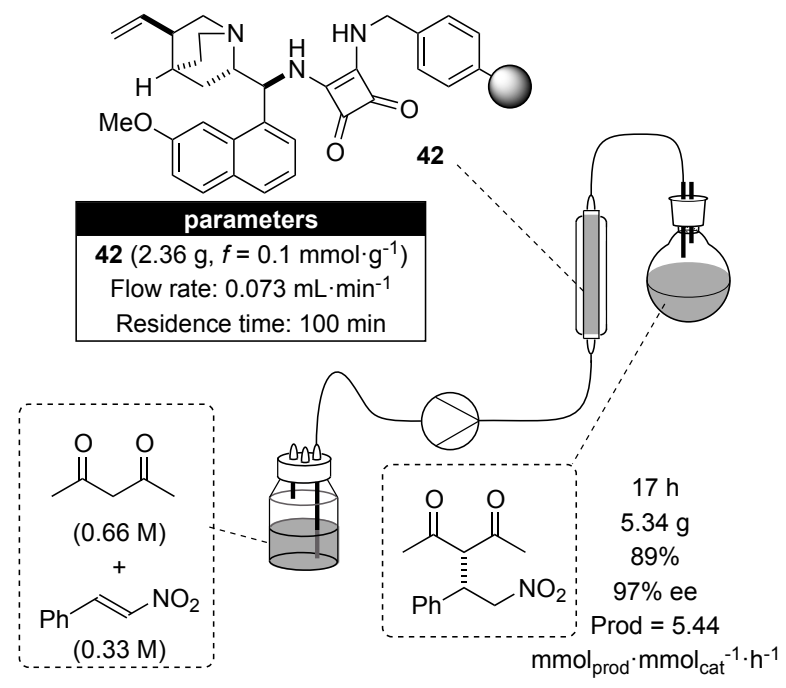

Figure 15. Michael addition catalyzed by a tether-free supported squaramide.

\subsection{Polystyrene-Supported Chiral Phosphoric Acids}

Chiral phosphoric acids (PA) are probably the Brønsted acid catalysts that have attracted more interest in the last years. ${ }^{[70 a-c, g]}$ Since the pioneering reports by Akiyama ${ }^{[80]}$ and Terada ${ }^{[81]}$ in 2004, plenty of authors have found countless applications for these extremely versatile species. Their mode of action has been recently expanded with the so-called Asymmetric Counteranion-Directed Catalysis (ACDC), introduced by List in 2006. ${ }^{[82]}$ Indeed, Rueping ${ }^{[83]}$ and Blechert ${ }^{[84]}$ have prepared immobilized $\mathrm{PA}^{[85]}$ that have been used in batch, showing that the system was amenable for multiple recycling. However, the features of those polymers did not 
allow the study of the reaction under flow conditions. The use of soluble chiral PA in flow has also been described, ${ }^{[8 \mathrm{~b}, \mathrm{c}]}$ but the nature of the approach precluded the possibility of taking advantage of the presumed catalyst robustness (see comparison in Figure 1).

To date, the only example of a solid-supported chiral PA used in flow has been reported by the Pericàs laboratory in 2014. ${ }^{[86]}$ The preparation of $\mathbf{4 3}$ entailed a rather long route but the final species could be easily purified by washing with acid, thus avoiding the adventitious formation of calcium or sodium phosphate salts. These impurities, easily formed upon chromatographic purification of the PA, can be difficult to tell apart from the protonated species. ${ }^{[87]}$ In some cases, the salts are as active as the acid, but in other situations they show no catalytic activity.

The chiral PA 43 was applied to the Friedel-Crafts addition of indoles to $N$-tosylimines, based on a procedure reported independently by You, ${ }^{[88]}$ Antilla ${ }^{[89]}$ and Terada ${ }^{[00]}$ in homogeneous phase. First, a continuous flow experiment run at $0.2 \mathrm{~mL} \cdot \mathrm{min}^{-1}$ was carried out for $6 \mathrm{~h}$, in which the $360 \mathrm{mg}$ of $\mathbf{4 3}$ showed no apparent deactivation. In this time, $3.6 \mathrm{~g}$ of $44 \mathrm{a}$ could be obtained in $94 \%$ ee (Figure 16).

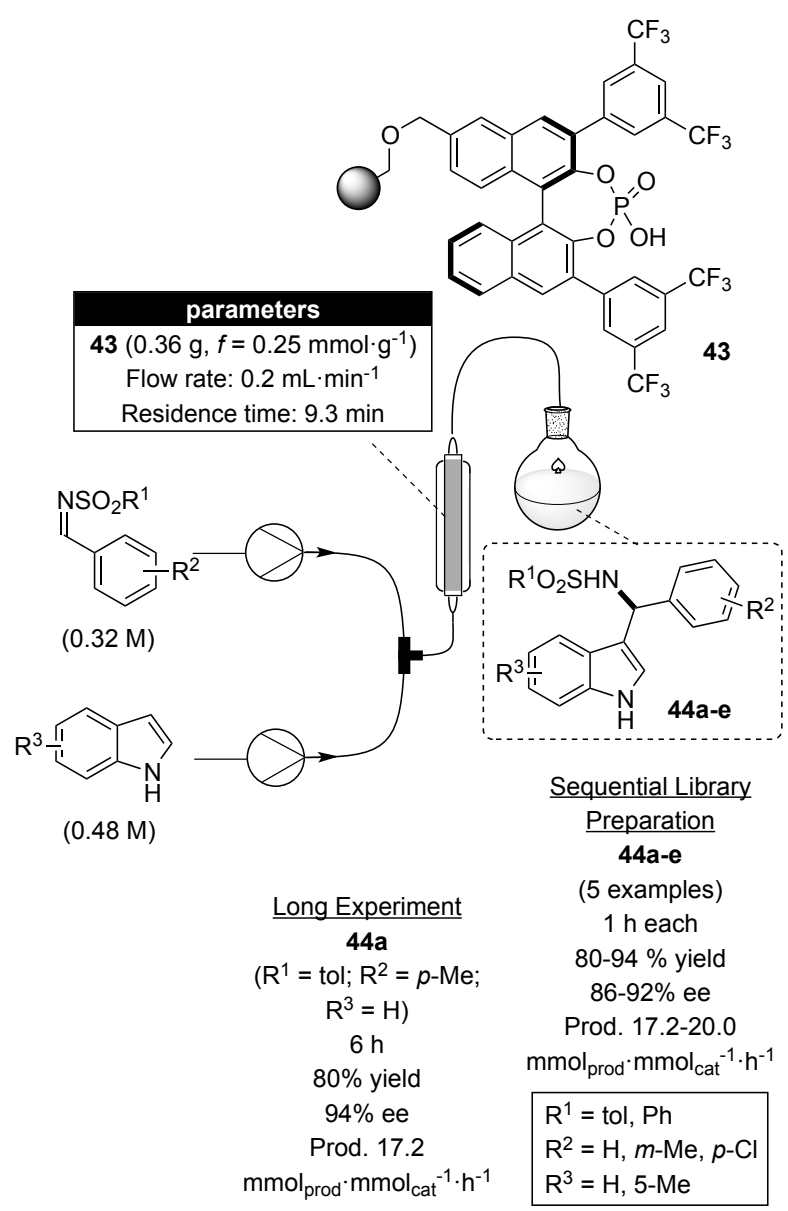

Figure 16. Chiral phosphoric acid $\mathbf{4 3}$ as a catalyst for the enantioselective Friedel-Crafts addition of indoles to $\mathrm{N}$-sulfonylimines.

Then, a sequential experiment similar to the one described above was used to generate a small library of five enantiopure analogues with three different points of diversity (Figure 16). Noteworthy, in the case of catalyst deactivation, simply washing the resin with $\mathrm{HCl}$ in EtOAc restored the initial levels of activity. This strategy allowed to carry out both the $6 \mathrm{~h}$-run and the preparation of the library with the same $360 \mathrm{mg}$ of 43 .

\section{Conclusions}

The combination of heterogenized chiral organocatalysts and flow techniques holds great promise for the sustainable production of enantioenriched compounds, with myriads of applications possible. However, and in spite of the pioneering efforts presented herein, there is work to be done before this field is considered mature. 
Probably the main limitation so far is the limited lifespan of most of the reported catalysts. Identifying the reasons behind this deactivation is not an easy task in homogeneous conditions, let alone in solid-supported species. However, rational design has allowed the preparation of more active and robust species and this trend is expected to continue in the future. Perhaps the other main challenge for the players in this field is to be able to integrate these systems in a complex set-up involving more than one step in flow, like several authors have demonstrated for continuous processing in organic synthesis. ${ }^{[91],[92]}$ The pioneering effort of Letcka also marked the path in this sense and those that will follow are sure to find application in industrial processes $^{[93]}$ and preparation of active pharmaceutical ingredients. ${ }^{[94]}$

\section{Acknowledgements}

Financial support by the MINECO (Grant CTQ2012-38594-C02-01), DEC Generalitat de Catalunya (Grant 2014SGR827), ICIQ Foundation and the EU-ITN network Mag(net)icFun (PITN-GA-2012-290248) is gratefully acknowledged. We also thank MINECO for support through Severo Ochoa Excellence Accreditation 20142018 (SEV-2013-0319). C. R.-E. acknowledges the Generalitat de Catalunya for a Beatriu de Pinós B fellowship.

Keywords: continuous flow chemistry $•$ solid-supported catalysts $\bullet$ enantioselective catalysis • organocatalysis - sustainability

1] A. A. Lapkin, P. W. Plucinski, Engineering Factors for Efficient Flow Processes in Chemical Industries, in S. V. Luis, E. GarciaVerdugo (Eds.), Chemical Reactions and Processes under Flow Conditions, RSC Publishing, Cambridge, 2010.

[2] a) K. Jähnisch, V. Hessel, H. Löwe, M. Baerns, Angew. Chem. Int. Ed. 2004, 43, 406-446; b) K. Geyer, J. D. C. Codée, P. H. Seeberger, Chem. Eur. J. 2006, 12, 8434-8442; c) B. P. Mason, K. E. Price, J. L. Steinbacher, A. R. Bogdan, D. T. McQuade, Chem. Rev. 2007, 107, 2300-2318; d) N. Kockmann, M. Gottsponer, B. Zimmermann, D. M. Roberge, Chem. Eur. J. 2008, 14, 7470-7477; e) C. Wiles, P. Watts, Eur. J. Org. Chem. 2008, 1655-1671; f) K. Geyer, T. Gustafsson, P. H. Seeberger, Synlett 2009, 2382-2391; g) R. L. Hartman, K. F. Jensen, Lab Chip 2009, 9, 2495-2507; h) K. S. Elvira, X. Casadevall i Solvas, R. C. R. Wootton, A. J. deMello, Nature Chem. 2013, 5, 905-915; i) A. A. Kulkarni, Beilstein J. Org. Chem. 2014, 10, 405-424; j) K. F. Jensen, B. J. Reizman, S. G. Newman, Lab Chip 2014, 14, 3206-3212.

[3] V. Hessel, Chem. Eng. Technol. 2009, 32, 1655-1681.

[4] a) J. C. Brandt, T. Wirth, Beilstein J. Org. Chem. 2009, 5, No. 30; b) P. Poechlauer, S. Braune, B. Dielemans, B. Kaptein, R. Obermüller, M. Thathagar, Chim. Oggi 2012, 30, 51-54

[5] T. Wirth, Microreactors in Organic Synthesis and Catalysis, Wiley-VCH, Weinheim, 2008.

[6] a) L. Vaccaro, D. Lanari, A. Marrocchi, G. Strappaveccia, Green Chem. 2014, 16, 3680-3704; b) C. Wiles, P. Watts, Green Chem. 2014, 16, 55-62.

[7] a) S. Bräse, F. Lauterwasser, R. E. Ziegert, Adv. Synth. Catal. 2003, 345, 869-929; b) X. Y. Mak, P. Laurino, P. H. Seeberger, Beilstein J. Org. Chem. 2009, 5, No. 19; c) T. Tsubogo, T. Ishiwata, S. Kobayashi, Angew. Chem. Int. Ed. 2013, 52, 6590-6604; d) D. Zhao, K. Ding, ACS Catal. 2013, 3, 928-944; e) A. Puglisi, M. Benaglia, V. Chiroli, Green Chem. 2013, 15, $1790-1813$.

[8] For selected examples, see: a) A. Odedra, P. H. Seeberger, Angew. Chem. Int. Ed. 2009, 48, 2699-2702; b) S. Fritzsche, S. Ohla, P. Glaser, D. S. Giera, M. Sickert, C. Schneider, D. Belder, Angew. Chem. Int. Ed. 2011, 50, 9467-9470; c) M. Rueping, T. Bootwicha, E. Sugiono, Beilstein J. Org. Chem. 2012, 8, 300-307.

[9] a) G. Jas, A. Kirschning, Chem. Eur. J. 2003, 9, 5708-5723; b) A. Kirschning, W. Solodenko, K. Mennecke, Chem. Eur. J. 2006, 12, 5972-5990; c) C. G. Frost, L. Mutton, Green Chem. 2010, 12, 1687-1703.

[10] a) D. E. De Vos, I. F. J. Vankelecom, P. A. Jacobs, Chiral Catalyst Immobilization and Recycling, Wiley-VCH, Weinheim, 2000; b) M. Benaglia, Recoverable and Recyclable Catalysts, Wiley-VCH, Weinheim, 2009; c) A. F. Trindade, P. M. P. Gois, C. A. M. Afonso, Chem. Rev. 2009, 109, 418-514.

[11] a) M. Benaglia, A. Puglisi, F. Cozzi, Chem. Rev. 2003, 103, 3401-3430; b) For reviews on solid-supported enantioselective organocatalysts, see: F. Cozzi, Adv. Synth. Catal. 2006, 348, 1367-1390; c) M. Benaglia, New J. Chem. 2006, 30, 1525-1533; d) M. Gruttadauria, F. Giacalone, R. Noto, Chem. Soc. Rev. 2008, 37, 1666-1688; e) T. E. Kristensen, T. Hansen, Eur. J. Org. Chem. 2010, 3179-3204.

[12] a) S. Minakata, M. Komatsu, Chem. Rev. 2008, 109, 711-724; b) E. L. Margelefsky, R. K. Zeidan, M. E. Davis, Chem. Soc. Rev. 2008, 37, 1118-1126; c) J. Lu, P. H. Toy, Chem. Rev. 2009, 109, 815-838; d) A. Zamboulis, N. Moitra, J. J. E. Moreau, X. Cattoën, M. Wong Chi Man, J. Mater. Chem. 2010, 20, 9322-9338.

[13] For general reviews on organocatalysis, see: a) P. I. Dalko, Enantioselective Organocatalysis. Reactions and Experimental Procedures, Wiley-VCH, Weinhein, 2007; b) D. Almaşi, D. A. Alonso, C. Nájera, Tetrahedron: Asymmetry 2007, 18, 299-365; c) D. W. C. MacMillan, Nature 2008, 455, 304-308; d) P. Melchiorre, M. Marigo, A. Carlone, G. Bartoli, Angew. Chem. Int. Ed. 2008, 47, 6138-6171; e) A. Dondoni, A. Massi, Angew. Chem. Int. Ed. 2008, 47, 4638-4660; f) S. Bertelsen, K. A. Jørgensen, Chem. Soc. Rev. 2009, 38, 2178-2189; g) C. Palomo, M. Oiarbide, R. Lopez, Chem. Soc. Rev. 2009, 38, 632-653; h) B. List (Ed.), Asymmetric Organocatalysis in Top. Curr. Chem. Vol. 291, Springer, Berlin, 2009

[14] For a review on the exception (i.e. low-loading asymmetric organocatalysis), see: F. Giacalone, M. Gruttadauria, P. Agrigento, R. Noto, Chem. Soc. Rev. 2012, 41, 2406-2447.

[15]a) S. Itsuno, K. Kamahori, K. Watanabe, T. Koizumi, K. Ito, Tetrahedron: Asymmetry 1994, 5, 523-526; b) S. Itsuno, K. Watanabe, T. Koizumi, K. Ito, React. Polym. 1995, 24, 219-227; c) K. Kamahori, S. Tada, K. Ito, S. Itsuno, Tetrahedron: Asymmetry 1995, 6 , 2547-2555.

[16] S. Itsuno, Y. Sakurai, K. Ito, T. Maruyama, S. Nakahama, J. M. J. Fréchet, J. Org. Chem. 1990, 55, 304-310. 
[17] S. Itsuno, J. M. J. Fréchet, J. Org. Chem. 1987, 52, 4140-4142.

[18] a) K. Soai, S. Niwa, M. Watanabe, J. Chem. Soc., Perkin Trans. 1 1989, 109-113; b) K. Soai, S. Niwa, M. Watanabe, J. Org. Chem. 1988, 53, 927-928.

[19] G. Liu, J. A. Ellman, J. Org. Chem. 1995, 60, 7712-7713.

[20] K. Kamahori, K. Ito, S. Itsuno, J. Org. Chem. 1996, 61, 8321-8324.

[21] A. M. Hafez, A. E. Taggi, H. Wack, W. J. Drury, T. Lectka, Org. Lett. 2000, 2, 3963-3965.

[22] R. Schwesinger, J. Willaredt, H. Schlemper, M. Keller, D. Schmitt, H. Fritz, Chem. Ber. 1994, 127, 2435-2454.

[23] A. M. Hafez, A. E. Taggi, T. Lectka, Chem. Eur. J. 2002, 8, 4114-4119.

[24] A. M. Hafez, A. E. Taggi, T. Dudding, T. Lectka, J. Am. Chem. Soc. 2001, 123, 10853-10859.

[25] A. M. Hafez, A. E. Taggi, H. Wack, J. Esterbrook, T. Lectka, Org. Lett. 2001, 3, 2049-2051.

[26] a) S. France, H. Wack, A. E. Taggi, A. M. Hafez, T. R. Wagerle, M. H. Shah, C. L. Dusich, T. Lectka, J. Am. Chem. Soc. 2004, 126, 4245-4255; b) H. Wack, A. E. Taggi, A. M. Hafez, W. J. Drury, T. Lectka, J. Am. Chem. Soc. 2001, 123, $1531-1532$.

[27] D. Bernstein, S. France, J. Wolfer, T. Lectka, Tetrahedron: Asymmetry 2005, 16, 3481-3483.

[28] S. France, D. Bernstein, A. Weatherwax, T. Lectka, Org. Lett. 2005, 7, 3009-3012.

[29] F. Bonfils, I. Cazaux, P. Hodge, C. Caze, Org. Biomol. Chem. 2006, 4, 493-497.

[30] For the pioneering report, see: B. List, R. A. Lerner, C. F. Barbas, J. Am. Chem. Soc. 2000, 122, 2395-2396.

[31]a) C. W. Tornøe, C. Christensen, M. Meldal, J. Org. Chem. 2002, 67, 3057-3064; b) V. V. Rostovtsev, L. G. Green, V. V. Fokin, K. B. Sharpless, Angew. Chem. Int. Ed. 2002, 41, 2596-2599; c) M. Meldal, C. W. Tornøe, Chem. Rev. 2008, 108, $2952-3015$.

[32] For a review on immobilization of catalysts via click chemistry, see: A. E. Fernandes, A. M. Jonas, O. Riant, Tetrahedron 2014, $70,1709-1731$.

[33]a) D. Font, C. Jimeno, M. A. Pericàs, Org. Lett. 2006, 8, 4653-4655; b) D. Font, S. Sayalero, A. Bastero, C. Jimeno, M. A. Pericàs, Org. Lett. 2008, 10, 337-340.

[34] Reviews on the organocatalytic Mannich reaction: a) A. Ting, S. E. Schaus, Eur. J. Org. Chem. 2007, 5797-5815; b) J. M. M. Verkade, L. J. C. v. Hemert, P. J. L. M. Quaedflieg, F. P. J. T. Rutjes, Chem. Soc. Rev. 2008, 37, 29-41.

[35] E. Alza, C. Rodríguez-Escrich, S. Sayalero, A. Bastero, M. A. Pericàs, Chem. Eur. J. 2009, 15, 10167-10172.

[36] a) F. Z. Dörwald, Organic Synthesis on Solid Phase, Wiley-VCH, Weinheim, 2002; b) J. Tulla-Puche, F. Albericio, The Power of Functional Resins in Organic Synthesis, Wiley-VCH, Weinheim, 2008.

[37] X. C. Cambeiro, R. Martín-Rapún, P. O. Miranda, S. Sayalero, E. Alza, P. Llanes, M. A. Pericàs, Beilstein J. Org. Chem. 2011, 7, 1486-1493.

[38] Pioneering reports on the asymmetric organocatalytic $\alpha$-oxidation of aldehydes with nitroso compounds: a) S. P. Brown, M. P. Brochu, C. J. Sinz, D. W. C. MacMillan, J. Am. Chem. Soc. 2003, 125, 10808-10809; b) Y. Hayashi, J. Yamaguchi, K. Hibino, M. Shoji, Tetrahedron Lett. 2003, 44, 8293-8296.

[39] A. Massi, A. Cavazzini, L. D. Zoppo, O. Pandoli, V. Costa, L. Pasti, P. P. Giovannini, Tetrahedron Lett. 2011, 52, 619-622.

[40] O. Bortolini, L. Caciolli, A. Cavazzini, V. Costa, R. Greco, A. Massi, L. Pasti, Green Chem. 2012, 14, 992-1000.

[41] A. L. W. Demuynck, L. Peng, F. de Clippel, J. Vanderleyden, P. A. Jacobs, B. F. Sels, Adv. Synth. Catal. 2011, 353, $725-732$.

[42] C. Ayats, A. H. Henseler, M. A. Pericàs, ChemSusChem 2012, 5, 320-325.

[43] R. Martín-Rapún, X. Fan, S. Sayalero, M. Bahramnejad, F. Cuevas, M. A. Pericàs, Chem. Eur. J. 2011, 17, 8780-8783.

[44] H. Zhang, S. Mitsumori, N. Utsumi, M. Imai, N. Garcia-Delgado, M. Mifsud, K. Albertshofer, P. H.-Y. Cheong, K. N. Houk, F. Tanaka, C. F. Barbas, J. Am. Chem. Soc. 2007, 130, 875-886.

[45] M. Pouliquen, J. Blanchet, M.-C. Lasne, J. Rouden, Org. Lett. 2008, 10, 1029-1032.

[46] R. Martín-Rapún, S. Sayalero, M. A. Pericàs, Green Chem. 2013, 15, 3295-3301.

[47] S. S. V. Ramasastry, H. Zhang, F. Tanaka, C. F. Barbas, J. Am. Chem. Soc. 2006, 129, 288-289.

[48] C. Ayats, A. H. Henseler, E. Dibello, M. A. Pericàs, ACS Catal. 2014, 4, 3027-3033.

[49]a) M. Marigo, T. C. Wabnitz, D. Fielenbach, K. A. Jørgensen, Angew. Chem. Int. Ed. 2005, 44, 794-797; b) J. Franzén, M. Marigo, D. Fielenbach, T. C. Wabnitz, A. Kjærsgaard, K. A. Jørgensen, J. Am. Chem. Soc. 2005, 127, 18296-18304.

[50] Y. Hayashi, H. Gotoh, T. Hayashi, M. Shoji, Angew. Chem. Int. Ed. 2005, 44, 4212-4215.

[51] For reviews on the use of diarylprolinols in organocatalysis, see: a) A. Mielgo, C. Palomo, Chem. Asian J. 2008, 3, 922-948; b) K. L. Jensen, G. Dickmeiss, H. Jiang, Ł. Albrecht, K. A. Jørgensen, Acc. Chem. Res. 2011, 45, 248-264.

[52] a) Y. Li, X.-Y. Liu, G. Zhao, Tetrahedron: Asymmetry 2006, 17, 2034-2039; b) M. C. Varela, S. M. Dixon, K. S. Lam, N. E. Schore, Tetrahedron 2008, 64, 10087-10090; c) B. G. Wang, B. C. Ma, Q. Wang, W. Wang, Adv. Synth. Catal. 2010, 352, 2923-2928; d) I. Mager, K. Zeitler, Org. Lett. 2010, 12, 1480-1483; e) C. A. Wang, Z. K. Zhang, T. Yue, Y. L. Sun, L. Wang, W. D. Wang, Y. Zhang, C. Liu, W. Wang, Chem. Eur. J. 2012, 18, 6718-6723; f) M. Keller, A. Perrier, R. Linhardt, L. Travers, S. Wittmann, A.-M. Caminade, J.-P. Majoral, O. Reiser, A. Ouali, Adv. Synth. Catal. 2013, 355, 1748-1754.

[53] E. Alza, S. Sayalero, X. Cambeiro, R. Martín-Rapún, P. Miranda, M. A. Pericàs, Synlett 2011, 464-468.

[54] a) E. Alza, M. A. Pericàs, Adv. Synth. Catal. 2009, 351, 3051-3056; b) E. Alza, S. Sayalero, P. Kasaplar, D. Almaşi, M. A. Pericàs Chem. Eur. J. 2011, 17, 11585-11595.

[55] Precedent in homogeneous: Y. Hayashi, M. Toyoshima, H. Gotoh, H. Ishikawa, Org. Lett. 2008, 11, 45-48.

[56]For the pioneering reports, see: a) B. List, J. Am. Chem. Soc. 2002, 124, 5656-5657; b) A. Bøgevig, K. Juhl, N. Kumaragurubaran, W. Zhuang, K. A. Jørgensen, Angew. Chem. Int. Ed. 2002, 41, 1790-1793.

[57] X. Fan, S. Sayalero, M. A. Pericàs, Adv. Synth. Catal. 2012, 354, 2971-2976.

[58] a) R. B. Merrifield, J. Am. Chem. Soc. 1963, 85, 2149-2154; b) R. B. Merrifield, Angew. Chem. Int. Ed. 1985, 24, 799-810.

[59] Y. Arakawa, M. Wiesner, H. Wennemers, Adv. Synth. Catal. 2011, 353, 1201-1206.

[60] Pioneering asymmetric organocatalytic Michael additions to nitroalkenes: a) J. M. Betancort, C. F. Barbas, Org. Lett. 2001, 3, 3737-3740; b) B. List, P. Pojarliev, H. J. Martin, Org. Lett. 2001, 3, 2423-2425.

[61] S. B. Ötvös, I. M. Mándity, F. Fülöp, ChemSusChem 2012, 5, 266-269.

[62] S. B. Ötvös, I. M. Mándity, F. Fülöp, J. Catal. 2012, 295, 179-185.

[63] Y. Arakawa, H. Wennemers, ChemSusChem 2013, 6, 242-245.

[64] For the ground-breaking report, see: K. A. Ahrendt, C. J. Borths, D. W. C. MacMillan, J. Am. Chem. Soc. 2000, 122, $4243-4244$.

[65] V. Chiroli, M. Benaglia, F. Cozzi, A. Puglisi, R. Annunziata, G. Celentano, Org. Lett. 2013, 15, 3590-3593. 
[66] R. Porta, M. Benaglia, V. Chiroli, F. Coccia, A. Puglisi, Isr. J. Chem. 2014, 54, 381-394.

[67] a) R. M. Heck, S. Gulati, R. J. Farrauto, Chem. Eng. J. 2001, 82, 149-156; b) F. Švec, T. B. Tennikova, Z. Deyl, Monolithic Materials, Preparation, Properties and Applications, Elsevier, Amsterdam, 2003.

[68] P. Riente, J. Yadav, M. A. Pericàs, Org. Lett. 2012, 14, 3668-3671.

[69] V. Chiroli, M. Benaglia, A. Puglisi, R. Porta, R. P. Jumde, A. Mandoli, Green Chem. 2014, 16, 2798-2806.

[70] For reviews on chiral Brønsted acid catalysts, see: a) S. J. Connon, Angew. Chem. Int. Ed. 2006, 45, 3909-3912; b) M. Terada, Chem. Commun. 2008, 4097-4112; c) A. Zamfir, S. Schenker, M. Freund, S. B. Tsogoeva, Org. Biomol. Chem. 2010, 8, 52625276; d) M. Rueping, A. Kuenkel, I. Atodiresei, Chem. Soc. Rev. 2011, 40, 4539-4549; e) J. Aleman, A. Parra, H. Jiang, K. A. Jørgensen, Chem. Eur. J. 2011, 17, 6890-6899; f) M. Tsakos, C. G. Kokotos, Tetrahedron 2013, 69, 10199-10222; g) D. Parmar, E. Sugiono, S. Raja, M. Rueping, Chem. Rev. 2014, 114, DOI: 10.1021/cr5001496.

[71] a) P. R. Schreiner, Chem. Soc. Rev. 2003, 32, 289-296; b) X. Yu, W. Wang, Chem. Asian J. 2008, 3, 516-532; c) Ł. Albrecht, H. Jiang, K. A. Jørgensen, Chem. Eur. J. 2014, 20, 358-368.

[72] M. Fleischmann, D. Drettwan, E. Sugiono, M. Rueping, R. M. Gschwind, Angew. Chem. Int. Ed. 2011, 50, $6364-6369$.

[73] S. Tomàs, R. Prohens, M. Vega, M. C. Rotger, P. M. Deyà, P. Ballester, A. Costa, J. Org. Chem. 1996, 61, $9394-9401$.

[74] J. P. Malerich, K. Hagihara, V. H. Rawal, J. Am. Chem. Soc. 2008, 130, 14416-14417.

[75] P. Kasaplar, P. Riente, C. Hartmann, M. A. Pericàs, Adv. Synth. Catal. 2012, 354, 2905-2910.

[76] P. Kasaplar, C. Rodríguez-Escrich, M. A. Pericàs, Org. Lett. 2013, 15, 3498-3501.

[77] W. Yang, D.-M. Du, Adv. Synth. Catal. 2011, 353, 1241-1246.

[78] General reviews on lab automation: a) M. D. Hopkin, I. R. Baxendale, S. V. Ley, Chim. Oggi 2011, 29, 28-33; b) P. P. Lange, K. James, ACS Comb. Sci. 2012, 14, 570-578; c) S. V. Ley, R. J. Ingham, M. O'Brien, D. L. Browne, Beilstein J. Org. Chem. 2013, 9 , 1051-1072.

[79] G. Kardos, T. Soós, Eur. J. Org. Chem. 2013, 4490-4494.

[80] T. Akiyama, J. Itoh, K. Yokota, K. Fuchibe, Angew. Chem. Int. Ed. 2004, 43, 1566-1568.

[81] D. Uraguchi, M. Terada, J. Am. Chem. Soc. 2004, 126, 5356-5357.

[82] a) S. Mayer, B. List, Angew. Chem. Int. Ed. 2006, 45, 4193-4195; b) M. Mahlau, B. List, Angew. Chem. Int. Ed. 2013, 52, 518533; c) K. Brak, E. N. Jacobsen, Angew. Chem. Int. Ed. 2013, 52, 534-561.

[83] M. Rueping, E. Sugiono, A. Steck, T. Theissmann, Adv. Synth. Catal. 2010, 352, 281-287.

[84] a) C. Bleschke, J. Schmidt, D. S. Kundu, S. Blechert, A. Thomas, Adv. Synth. Catal. 2011, 353, 3101-3106; b) D. S. Kundu, J. Schmidt, C. Bleschke, A. Thomas, S. Blechert, Angew. Chem. Int. Ed. 2012, 51, 5456-5459.

[85] A. K. Mutyala, N. T. Patil, Org. Chem. Front. 2014, 1, 582-586.

[86] L. Osorio-Planes, C. Rodríguez-Escrich, M. A. Pericàs, Chem. Eur. J. 2014, 20, 2367-2372.

[87] M. Klussmann, L. Ratjen, S. Hoffmann, V. Wakchaure, R. Goddard, B. List, Synlett 2010, 2189-2192.

[88] Q. Kang, Z.-A. Zhao, S.-L. You, J. Am. Chem. Soc. 2007, 129, 1484-1485.

[89] G. B. Rowland, E. B. Rowland, Y. Liang, J. A. Perman, J. C. Antilla, Org. Lett. 2007, 9, 2609-2611.

[90] M. Terada, S. Yokoyama, K. Sorimachi, D. Uraguchi, Adv. Synth. Catal. 2007, 349, 1863-1867.

[91] For reviews, see: a) D. Webb, T. F. Jamison, Chem. Sci. 2010, 1, 675; b) J. C. Pastre, D. L. Browne, S. V. Ley, Chem. Soc. Rev. 2013, 42, 8849-8869; c) J. Wegner, S. Ceylan, A. Kirschning, Adv. Synth. Catal. 2012, 354, 17-57.

[92] Selected examples of multi-step organic synthesis in flow: a) I. R. Baxendale, C. M. Griffiths-Jones, S. V. Ley, G. K. Tranmer, Synlett 2006, 427-430; b) I. R. Baxendale, J. Deeley, C. M. Griffiths-Jones, S. V. Ley, S. Saaby, G. K. Tranmer, Chem. Commun. 2006, 2566-2568; c) H. Usutani, Y. Tomida, A. Nagaki, H. Okamoto, T. Nokami, J.-i. Yoshida, J. Am. Chem. Soc. 2007, 129, 3046-3047; d) T. L. LaPorte, M. Hamedi, J. S. DePue, L. Shen, D. Watson, D. Hsieh, Org. Process Res. Dev. 2008, 12, 956-966; e) I. R. Baxendale, S. V. Ley, A. C. Mansfield, C. D. Smith, Angew. Chem. Int. Ed. 2009, 48, 4017-4021; f) A. R. Bogdan, S. L. Poe, D. C. Kubis, S. J. Broadwater, D. T. McQuade, Angew. Chem. Int. Ed. 2009, 48, 8547-8550; g) T. P. Petersen, A. Ritzén, T. Ulven, Org. Lett. 2009, 11, 5134-5137; h) R. L. Hartman, J. R. Naber, S. L. Buchwald, K. F. Jensen, Angew. Chem. Int. Ed. 2010, 49, 899-903; i) M. Brasholz, J. M. Macdonald, S. Saubern, J. H. Ryan, A. B. Holmes, Chem. Eur. J. 2010, 16, 11471-11480; j) E. Riva, A. Rencurosi, S. Gagliardi, D. Passarella, M. Martinelli, Chem. Eur. J. 2011, 17, 6221-6226; k) F. Lévesque, P. H. Seeberger, Angew. Chem. Int. Ed. 2012, 51, 1706-1709; I) S. Mascia, P. L. Heider, H. Zhang, R. Lakerveld, B. Benyahia, P. I. Barton, R. D. Braatz, C. L. Cooney, J. M. B. Evans, T. F. Jamison, K. F. Jensen, A. S. Myerson, B. L. Trout, Angew. Chem. Int. Ed. 2013, 52, 12359-12363; m) L. Dalla-Vechia, B. Reichart, T. Glasnov, L. S. M. Miranda, C. O. Kappe, R. O. M. A. de Souza, Org. Biomol. Chem. 2013, 11, 6806-6813; n) M. D. Hopkin, I. R. Baxendale, S. V. Ley, Org. Biomol. Chem. 2013, 11, $1822-1839$.

[93] P. T. Baraldi, V. Hessel, Green Process. Synth. 2012, 1, 149-167.

[94] L. Malet-Sanz, F. Susanne, J. Med. Chem. 2012, 55, 4062-4098. 
Miquel A. Pericàs (Ciutat de Mallorca, 1951) obtained his doctorate in 1979 under the guidance of Prof. Fèlix Serratosa at the Universitat de Barcelona. After postdoctoral studies at the Spanish research council (CSIC) with Prof. Francesc Camps, he joined the Universitat de Barcelona as Assistant Professor in 1980 and was promoted to Full Professor in 1991. In June 2000, he was appointed to found the Institute of Chemical Research of Catalonia (ICIQ) where he now

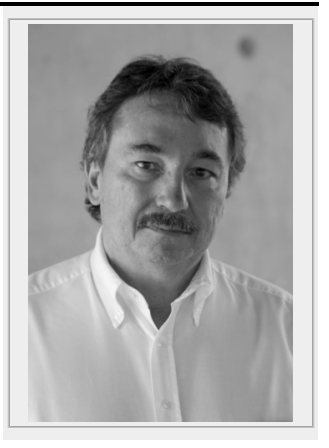
serves as Director and Group Leader. His major research interest is focused on asymmetric catalysis with immobilized species for the development of flow processes allowing the continuous production of enantiomerically pure compounds.

Carles Rodríguez-Escrich (Barcelona, 1980) obtained his $\mathrm{PhD}$ from the Universitat de Barcelona in 2008, after completing the total synthesis of Amphidinolide $X$ under the supervision of Profs. Vilarrasa and Urpí. After that he moved to the Pericàs laboratory at the ICIQ (Tarragona) to work with polystyrenesupported (organo)catalysts and flow chemistry. He then spent two years (20102012) in the group of Prof. Karl Anker Jørgensen at the University of Aarhus, developing new organocatalytic

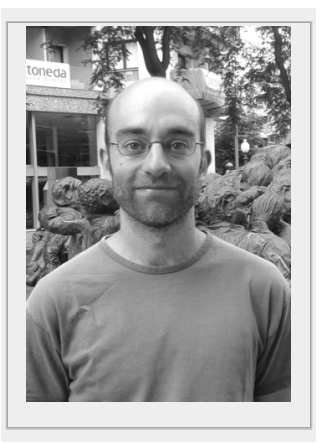

enantioselective methods. In September 2012 he returned to the ICIQ where he is currently a group coordinator at the Pericàs laboratory.

\section{MICROREVIEW}

Modern continuous flow techniques are reshaping the chemical landscape by providing tools for more efficient chemical processes. Enantioselective catalysis can also benefit from these advantages and the combination of these two fields is a perfect match in terms of sustainable chemical practices. In this review we will focus on the use of immobilized organocatalysts to promote enantioselective processes in flow.

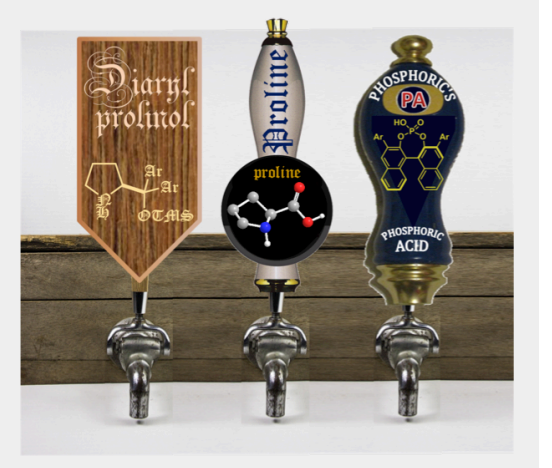

Carles Rodríguez-Escrich* and Miquel A. Pericàs*

Organocatalysis on Tap: Enantioselective Continuous Flow Processes Mediated by SolidSupported Chiral Organocatalysts 